\title{
PUBLIC INTERNATIONAL FUNDING OF NATURE-BASED SOLUTIONS FOR ADAPTATION: A LANDSCAPE ASSESSMENT
}

STACY SWANN, LAURENCE BLANDFORD, SHELDON CHENG, JONATHAN COOK, ALAN MILLER, AND RHONA BARR

\section{EXECUTIVE SUMMARY}

\section{Highlights}

Overall, the amount of public international funding flowing to nature-based solutions (NbS) for adaptation is still relatively small, accounting for only US $\$ 3.8-8.7$ billion, or approximately $0.6-1.4$ percent of total climate finance flows ${ }^{1}$ and $1.5-3.4$ percent of public climate finance flows, in 2018.

- Funding for NbS for adaptation (NbSA) in 2018 was driven by a handful of major bilateral donors, including Germany, the United Kingdom, Japan, and Sweden. The European Union, Asian Development Bank, the Green Climate Fund, and the International Fund for Agricultural Development were among the largest multilateral donors and channels of funding. Countries in Sub-Saharan Africa and South and Central Asia received approximately 50 percent of total public $\mathrm{NbSA}$ funding.

- Funding in 2018 came primarily through grants. Though grants may play an important role, utilizing a broader range of instruments for NbSA may increase the opportunities to crowd in and catalyze private capital with public concessional finance.

- The absence of clear definitions, guidelines, and metrics and methodologies to track, quantify, and value NbSA benefits may significantly inhibit the development and financing of a robust pipeline of NbSArelated investments.

- Some NbSA projects do not provide reliable revenue streams, making it important to find other ways to fund long-term operational costs. To scale up and mobilize additional sources of funding, the full economic and financial case for NbSA-including cobenefits-needs to be clearly communicated.

\section{CONTENTS}

Executive Summary ...................................

1. Introduction ........................................ 3

2. The Current Funding Landscape ................. 6

3. Barriers and Challenges ......................... 13

4. Opportunities and Promising Approaches...........17

5. Recommendations ................................. 23

6. Conclusion ........................................... 30

Appendix A ...................................... 31

Appendix B ......................................... 36

Abbreviations .......................................... 37

Glossary .......................................... 38

Endnotes......................................... 39

References ........................................ 40

Acknowledgments................................. 47

Working Papers contain preliminary research, analysis, findings, and recommendations. They are circulated to stimulate timely discussion and critical feedback, and to influence ongoing debate on emerging issues. Working papers may eventually be published in another form and their content may be revised.

Suggested Citation: Swann, S., L. Blandford, S. Cheng, J. Cook, A. Miller, and R. Barr. 2021. "Public International Funding of Nature-based Solutions for Adaptation: A Landscape Assessment." Working Paper. Washington, DC: World Resources Institute. Available online at https://doi.org/10.46830/ wriwp.20.00065. 
The 2019 flagship report Adapt Now: A Global Call for Leadership on Climate Resilience by the Global Commission on Adaptation (the Commission) identified access to finance as one of three key barriers that impede the scaling up of NbSA in many countries. NbSA encompasses several different types of activities, investments, and approaches that seek to protect and restore nature and ecosystems for the services they provide to human society. ${ }^{2}$ Although various funding sources may exist, an individual country's ability to access them depends on a range of factors, including readiness and capacity, knowledge, and foresight to plan NbSA investments and the skills to finance such investments. For many developing countries, these efforts may be further complicated due to overall economic challenges and those now resulting from the COVID-19 pandemic. Meanwhile, interest in NbSA investment is changing quickly, with new actors, approaches, and investors seeking opportunities to invest in newly emerging NbSA in recent years.

NbSA investments will be fundamentally important in helping many countries address climate change. In almost all circumstances, public capital will be highly valuable. Climate finance and official development assistance (ODA) will be important to help developing countries scale up such investments, particularly where national public budgets may be constrained. Furthermore, because of the range of development and other benefits that NbSA can bring, integrating such approaches into postCOVID economic recovery planning can maximize the effectiveness of international and domestic public funding while delivering long-term resilience.

Demand exists. Seddon et al. (2019) showed that more than 60 percent of countries recognize the need to preserve ecosystems and have included NbS into their first nationally determined contributions (NDCs). Likewise, a similarly high number of countries acknowledge that protecting ecosystems and enhancing biodiversity is a key goal of their adaptation planning efforts.

This paper provides the first assessment of the landscape of public international funding (climate finance and ODA) for NbSA and seeks to help donor and developing countries better understand the current state of funding flowing for NbSA. The findings in this paper are based on an assessment of funding flows as well as interviews with key stakeholders, such as donors, climate finance funds, multilateral development banks, and countries.
The landscape assessment has some very important constraints. It covers only public international funding (not domestic budgets), and estimates are based on imperfect tagging within the data sets analyzed. Because the data sets analyzed do not explicitly tag $\mathrm{NbS}$ or NbSA, the authors tracked funding from sectors that most commonly align with NbSA, such as forestry or water. The assessment, therefore, is unlikely to capture all funding for NbSA. (More detail on the methodology can be found in Appendix A.)

The figures cited as the most definitive measure of total climate finance flows come from the Climate Policy Initiative (CPI) and include public, private, and some south-south flows. CPI's figures provide context for the NbSA estimates in this paper because their tracking is the most common citation for international and policy discussions around climate finance. ${ }^{3}$ This landscape assessment covers only public international funding. It shows that in 2018 public international finance for NbSA was estimated to account for $\$ 3.8-\$ 8.7$ billion-or 0.61.4 percent of total climate finance flows, $1.5-3.4$ percent of total public climate finance flows, and 9-21 percent of adaptation flows ${ }^{4}$-and relative to more than $\$ 140$ billion per year in adaptation investment needs in developing countries (UNEP 2021). ${ }^{5}$ Furthermore, CPI estimates that total funding for both adaptation and mitigation in the "agriculture, forestry, land-use, and natural resource management" sectors in 2018 only accounted for 3 percent of all tracked climate finance or 7 percent of tracked public finance (Buchner et al. 2019). Although not entirely comparable due to the mitigation activities in these sectors, this figure is often referenced as a data point to indicate overall $\mathrm{NbS}$ flows.

In 2018, the largest bilateral donors for NbSA included Germany, the United Kingdom, Japan, and Sweden. The European Union, Asian Development Bank, Green Climate Fund, and the International Fund for Agricultural Development were among the largest multilateral donors and channels of funding. Grants were, by far, the most common funding modality, accounting for as much as 85 percent of funds deployed to developing countries. Sub-Saharan Africa, South Asia, and Latin America and the Caribbean received the greatest volume of funding for NbSA. Although each country's use of international support is different, agriculture, general environmental protection, ${ }^{6}$ and biodiversity are the most common sectors in which ODA funding directed toward NbSA was spent. 
This paper also identifies barriers in the ODA funding landscape that, if addressed, can help donors maximize the impact of their public capital to accelerate these muchneeded investments. These barriers also, directly and indirectly, contribute to the lack of pipeline and inhibit the development of NbSA projects. Key barriers include the following:

\section{No common definition of NbSA exists.}

Countries, as well as other key stakeholders, still lack clarity around what constitutes adaptationfocused NbS. This confusion is most evident in international tracking systems (e.g., the Organisation for Economic Co-operation and Development's statistics database) and within countries, and it likely inhibits the potential pipeline of NbSA investments.

No clear metrics exist to value NbSA. Interviewees for this paper noted the need for metrics and methodologies to measure NbSA benefits and stated that the lack of such makes it difficult for developing countries, project developers, development institutions, and investors to appraise and compare NbSA options against other investment options; thus, they often are not prioritized.

- Donor sources of funding do not align with needs. Donor funding sources, where available, are insufficient in volume to meet all NbSA needs (measured by the potential demand evidenced through a country's NDC and national adaptation plan). Donor sources have primarily been in the form of grant capital. Many interviewees noted that NbSA projects need ongoing funding to support longer-term operational costs. This results in a significant funding gap that neither private investors nor developing countries can bear.

\section{Channels of donor funding do not explicitly} promote NbSA. Climate finance channels do not provide clear, specific guidance on how their funding can be used to support NbSA investments.

\section{Challenges in developing the NbSA pipeline} hinder access to financing. At both the national and subnational level, developing countries may lack the technical capacity to integrate NbSA into their adaptation planning and sufficiently develop NbSA projects and/or the NbSA project pipeline.

This paper puts forward four recommended actions to address these barriers hindering public donor funding support for NbSA. These recommended actions for public donors complement recommendations from reports that focus on mobilizing private capital for NbSA (see Box 4 in Section 5).

\section{Scale and better track ODA funding for NbSA.} Donors should scale up the ODA allocated for NbSA, help to ensure accounting mechanisms better track flows, and provide the technical support to help developing countries develop and finance NbSA investments.

\section{Better align ODA funding that is flowing. Cur-} rent ODA funding needs to be more closely aligned with individual NbSA project needs. Public funding is valuable to build capacity, prepare projects, and crowd in private capital. Donors should consider a more strategic application of public funding through flexible mechanisms, including concessional instruments to crowd in capital and grant support (where needed) over the life of the project where operational costs are unable to be borne by local governments or others.

Define, quantify, value, and measure NbSA benefits. Donors should develop, adopt, and accelerate a common approach to quantify and value NbSA benefits in ways that are meaningful for investment decision-making by a variety of public and private investors.

- Mainstream and build the pipeline of NbSA investment in developing countries. Donor funding should support efforts by developing countries to both mainstream NbSA into national adaptation and development-related policies, budgets, and investment plans and build a pipeline of NbSA investments at the country level, through capacity building, project preparation, and technical assistance for developing countries.

\section{INTRODUCTION}

\subsection{Background}

Nature-based solutions ( $\mathrm{NbS}$ ) are defined as "actions to protect, sustainably manage, and restore natural or modified ecosystems, that address societal challenges effectively and adaptively, simultaneously providing human well-being and biodiversity benefits" (World Conservation Congress 2016).

In recent years, awareness has increased about the importance of investing in NbS to both mitigate and adapt to climate change (Griscom et al. 2017). Attention 
has focused on identifying promising approaches and developing initiatives that can scale finance for $\mathrm{NbS}$ for adaptation (NbSA), often through innovative mechanisms that blend public capital to catalyze and leverage private capital (see Box 1 for definitions used in this paper). NbSA projects are inherently complex, often delivering public goods that may imply longer-term returns on investment and entail bringing together a broad range of stakeholders to address systemic community and societal challenges (Seddon et al. 2020a). Nonetheless, the benefits of NbSA are significant (Figure 1) for their flexibility in terms of context, utility, and cost efficiency (UNEP 2021).

Furthermore, while awareness has grown, so has interest in funding and implementing these approaches. For example, 62 percent of all first NDCs (104 out of 168) include $\mathrm{NbS}$ as adaptation actions, ${ }^{7}$ and 63 percent of nationally determined contributions (NDCs) declare that the protection of ecosystems and/or biodiversity is the intended outcome of adaptation planning (Seddon et al. 2019). Additionally, 19 national adaptation plans (NAPs) submitted to the United Nations Framework Convention on Climate Change (UNFCCC) by March 2020 included NbSA and/or ecosystem-based adaptation (EbA; Terton and Greenwalt 2020).

There is a significant overall funding gap for adaptation, of which NbSA are a part. In its Adaptation Gap Report 2020, the United Nations Environment Programme (UNEP) identified adaptation investment needs of more than US $\$ 140$ billion per year by 2030 (UNEP 2021). The Climate Policy Initiative (CPI) estimates that only $\$ 30$ billion in (mostly public) funding flowed for adaptation in 2018 (Buchner et al. 2019).

\section{Box 1 | Definitions: NbS, NbSA, EbA, and Eco-DRR}

Nature-based solutions (NbS) can be used for a variety of objectives, including climate change mitigation and/or adaptation, biodiversity conservation, and disaster risk reduction. This paper will focus on NbS that is used primarily for adaptation (NbSA). Note that NbS can often cut across sectors and provide multiple cobenefits; thus, although the focus of the paper is on NbSA, many of these NbS will provide benefits for biodiversity and mitigation as well.

$\mathrm{NbSA}$, also known as ecosystem-based adaptation (EbA), is defined thusly by various organizations:

IUCN" and CBD": "EbA is the use of biodiversity and ecosystem services as part of an overall adaptation strategy to help people to adapt to the adverse effects of climate change."

UNEPc: "[EbA] uses biodiversity and ecosystem services as part of an overall adaptation strategy to help people and communities adapt to the negative effects of climate change at local, national, regional, and global levels."

European Commission: "EbA refers to physical measures or management actions that utilize natural or ecosystem-like processes to adapt to a variety of climate hazards."

$\mathrm{NbSA}$ can be categorized under different use cases, including agriculture, forestry, coastal, urban, water management, and disaster risk reduction. NbS for disaster risk reduction are sometimes known as ecosystem-based disaster risk reduction (Eco-DRR).

These definitions of NbSA inform the methodology in Box 3.

Notes: a. International Union for Conservation of Nature; b. Convention on Biological Diversity; c. United Nations Environment Programme.

Sources: McVittie et al. 2017; SCBD 2009; Travers et al. 2012.

Figure 1 | Relationships between the Natural Environment and Climate Change Adaptation by Sector

\section{THE NATURAL ENVIRONMENT SUPPORTS RESILIENCE ACROSS SECTORS}

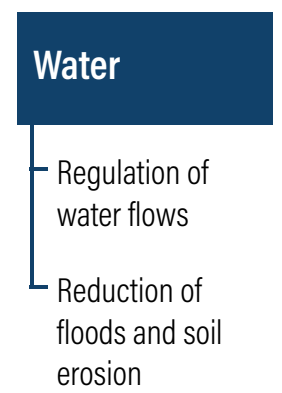

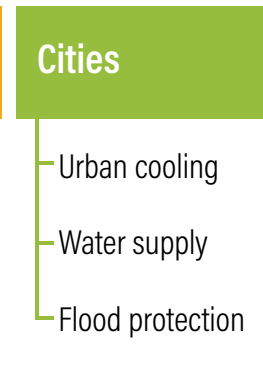

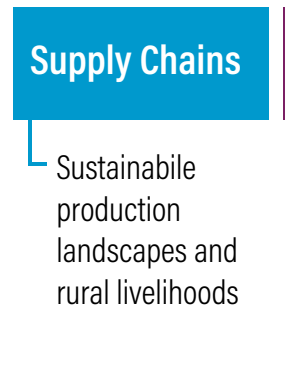

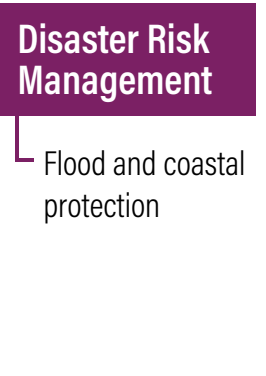

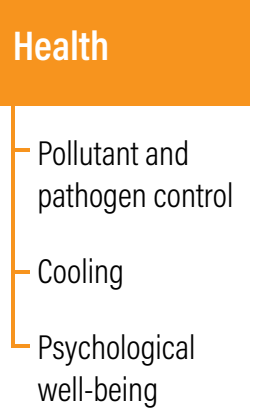


Figure 2 | The Relationship between NbS Finance for Adaptation, Climate Finance, and Conservation Finance

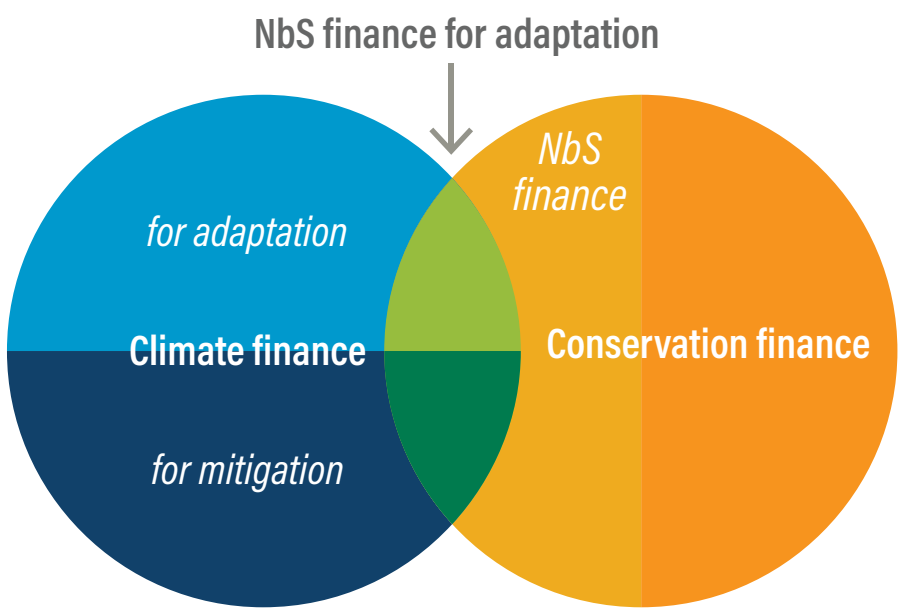

Notes: $\mathrm{NbS}=$ nature-based solutions

Source: UNEP 2021.

To date, there is no estimate of the total NbSA investment needed, although some estimates exist for related subsectors of NbSA (Figure 2 shows the relationship between these subsectors). For example, Financing Nature: Closing the Global Biodiversity Financing Gap estimated a current biodiversity conservation financing gap of between $\$ 598$ billion and $\$ 824$ billion per year (Deutz et al. 2020). Nevertheless, the report by the Global Commission on Adaptation (the Commission) highlighted access to finance as one of three key barriers that impede the scaling up of investment in $\mathrm{NbS}$ (Global Commission on Adaptation 2019).

In addition to the challenges of quantifying the NbSA funding gap, little analysis has been done of the amounts, types, and channels of public international funding to support NbS in developing countries. Given the importance of public capital in funding NbSA, a better understanding of these sources of funding is needed.

\subsection{About This Working Paper}

This paper provides an assessment of the landscape of public international funding for NbSA and seeks to help donor and developing countries better understand the current state of funding for NbSA. The findings in this paper are based on the sources in Box 2. This paper's primary audience is public donors providing funding for NbSA; a secondary audience is developing countries looking to fund NbSA as part of their climate action plans, as a number of the findings and recommendations relate to enabling better, more efficient use of public expenditure for NbSA regardless of its origin.

This paper assesses the current landscape of public funding sources for official development assistance (ODA) available to developing countries for NbSA by

estimating public international flows for NbSA;

describing key funders and modalities of current funding sources;

- identifying challenges and barriers that may prevent increased funding for NbSA unless addressed; and

- illustrating through examples several promising approaches for programming public funding, including those that catalyze private investment in NbSA.

The paper concludes with actionable recommendations to improve the provision and application of public international donor funding for NbSA.

This assessment is meant to complement other ongoing research related to financing $\mathrm{NbSA}$, including recent studies related to innovative financial instruments (e.g., insurance, results-based payments) and those assessing the potential to mobilize private investment for NbSA. It is also meant to complement other efforts to quantify climate finance flows writ large (e.g., CPI's climate finance landscape). ${ }^{8}$

\section{Box 2 | Sources Used for This Report}

The findings in this report are based on three main sources:

- The Organisation for Economic Co-operation and Development's Creditor Reporting System Aid Activity Database and other online research.

- A literature review, including information related to NbSA from donors, funding channels, developing country governments, and project developers.

- Surveys and interviews with key stakeholders (bilateral donors, development finance institutions, climate funds, developing country officials, etc.). 


\section{THE CURRENT FUNDING LANDSCAPE}

This assessment uses the Creditor Reporting System (CRS) database of the Organisation for Economic Cooperation and Development (OECD) to estimate a range (lower and upper bound) of public international funding for NbSA using 2012, 2015, and 2018 data sets of project commitments. The methodology for this assessment is described below and is further detailed in Appendix A, which describes which OECD data codes were used, how the methodology filtered out commitments for $\mathrm{NbS}$ that may not be for adaptation activities, and other issues.

Estimates are based on the OECD's CRS database. All CRS projects are classified by sector, and some are tagged with the Rio markers (which indicate either the primary or significant intent of the funding, such as mitigation, adaptation, or biodiversity). Although sector classifications are exclusive-a funding flow cannot be tagged with more than one sector-markers are not exclusive, meaning funding flows can be tagged with more than one marker.

As a result, our lower-bound estimates represent a narrower assessment of funding flows for NbSA but do not include funding from and through the multilateral channels, such as multilateral development banks (MDBs) or climate funds, due to how multilateral data is reported to the OECD. Our upper-bound estimates represent a broader assessment that loosens restrictions on both sectors and Rio marker tags; as a result, they may include some funding that does not primarily support NbSA objectives.

Please see Appendix A for a full description of the methodology used in this paper. In addition, Box 3 describes the limitations of the methodology.

\subsection{The Public international Funding Landscape}

It is estimated that in 2018, public donor finance for NbSA accounted for, conservatively, approximately 0.6 percent of total climate finance flows, 1.5 percent of public climate finance flows, and 9.0 percent of overall adaptation flows (Figure 3$).{ }^{9}$

Figure 4 provides an overview of the landscape of NbSA funding in 2018, highlighting the largest funders and channels for NbSA.

As shown below in Table 1 and Figure 5, tracked public funding for NbSA has increased over the years analyzed, from $\$ 2.1-\$ 4.1$ billion in 2012 to $\$ 3.8-\$ 8.7$ billion in 2018. For the years analyzed, the top ODA funders of NbSA were also among the top adaptation funders overall. Germany and the United Kingdom contributed

\section{Box 3 | The Limitations of the Methodology}

This paper does not capture flows beyond official development assistance (ODA) and nonconcessional development finance, such as domestic public financing and private financing; thus, the estimates provided herein are certainly an underestimate of the total flows for nature-based solutions for adaptation (NbSA).

Due to challenges in the available data sources, the information is only representative of the specific Organisation for Economic Co-operation and Development (OECD) data set used for this analysis. The methodology estimates

- general funding trends;

- top donor and recipient regions; and

- countries and uses (sectors).

There are likely investments in specific sectors (e.g., forests) that may include adaptation cobenefits and elements but may not have been reported or captured as NbSA. These issues may be further compounded because $\mathrm{NbSA}$-and adaptation more broadly-often cuts across sectors; thus, the reporting and categorization of funding for NbSA is challenging. Also, there is likely a portion of NbS-related funding that, although principally focused on biodiversity conservation and/or climate mitigation, may have unreported adaptation elements or insufficiently assessed adaptation benefits that are thus not captured in this analysis.

The information presented shows only data reported within the OECD and therefore may miss funding provided through or by some donors or funding institutions (such as the World Bank) that are not included in the system. For this reason, it likely underestimates public NbSA flows.

In sum, the constraints on the methodology reflect the limitations of the data sets available as well as definitional and reporting challenges that affect both $\mathrm{NbS}$ and adaptation finance writ large. 
Figure 3 | Estimated ODA for NbSA in the Context of Total Climate Finance Flows in 2018

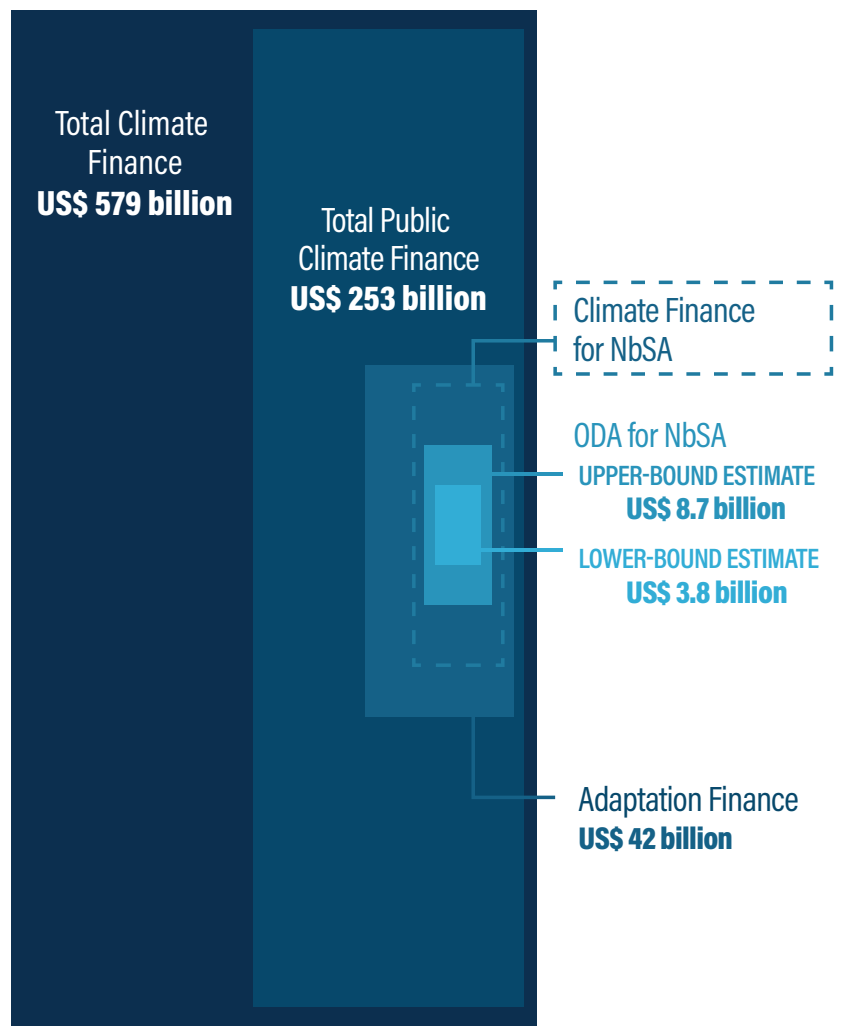

Note: The $\$ 42$ bn adaptation finance estimate refers to both adaptation-specific flows and those that have dual adaptation and mitigation benefits.

Source: Buchner et al. 2019.

significantly to the increase in ODA for NbSA funding between 2012 and 2018 (see Figure 6). Notably, a significant proportion (over 50 percent) of Germany's ODA in the analyzed sectors was for NbSA initiatives.

The lower bound estimates for multilateral organizations are assumed to be zero because these organizations did not use the biodiversity Rio marker. As noted in Box 3, the information presented includes only data reported within the OECD. As such, it may miss funding provided through or by some donors (bilateral or multilateral sources), and it may underreport some sources, such as the Global Environment Facility (GEF), for the years assessed. ${ }^{10}$
Table 1 | ODA Funding for NbSA (USȘ, millions)

\begin{tabular}{|c|c|c|c|c|}
\hline & DONOR & 2012 & 2015 & 2018 \\
\hline \multirow{5}{*}{$\begin{array}{l}\frac{1}{4} \\
\frac{\mathrm{m}}{\mathrm{m}} \\
\frac{\mathrm{m}}{\mathrm{m}}\end{array}$} & Germany & $420-550$ & $730-1,050$ & $920-1,510$ \\
\hline & United Kingdom & $0-70$ & $210-400$ & $850-890$ \\
\hline & Sweden & $90-160$ & $100-130$ & $260-360$ \\
\hline & Japan & $330-590$ & $20-470$ & $230-450$ \\
\hline & United States & $290-430$ & $180-350$ & $110-220$ \\
\hline \multirow{7}{*}{ 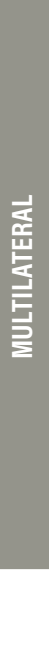 } & $\begin{array}{l}\text { Asian Development } \\
\text { Bank }\end{array}$ & - & - & $0-1,580$ \\
\hline & $\begin{array}{l}\text { European Union } \\
\text { institutions }\end{array}$ & $380-750$ & $340-1,000$ & $790-1,560$ \\
\hline & Green Climate Fund & - & $0-40$ & $0-460$ \\
\hline & $\begin{array}{l}\text { International Fund } \\
\text { for Agricultural } \\
\text { Development }\end{array}$ & - & $0-460$ & $0-250$ \\
\hline & $\begin{array}{l}\text { Global Environment } \\
\text { Facility }\end{array}$ & - & $0-110$ & $0-180$ \\
\hline & Adaptation Fund & $0-40$ & $0-50$ & $0-55$ \\
\hline & $\begin{array}{l}\text { Total of all ODA } \\
\text { funding for NbSA }\end{array}$ & $2,130-4,170$ & $2,690-6,230$ & $3,750-8,700$ \\
\hline
\end{tabular}

Note: $\mathrm{NbSA}=$ nature-based solutions for adaptation; $\mathrm{ODA}=$ official development assistance . Source: Based on raw data from OECD.Stat database, Creditor Reporting System, modified by the authors.

In fact, the MDBs, including the World Bank, InterAmerican Development Bank (IDB), European Bank for Reconstruction and Development, and others, typically support NbSA. However, these institutions may be reporting NbSA projects under different categories, or they may not be reporting as comprehensively to show a full picture of the landscape of funding flowing from these organizations. Also, given the recent rise in interest in $\mathrm{NbSA}$, a landscape assessment for 2020 might include a wider range of bilateral and multilateral funders.

For more details on how the upper and lower bounds were constructed, please see Appendix A. 
Figure 4 | The Landscape of ODA for NbSA Funding, 2018 (US\$, millions)

\section{SOURCES AND INTERMEDIARIES}

Germany

UB: $\$ 1,500$

$L B: \$ 920$

Others

UB: $\$ 1,100$

$L B: \$ 500$

UB: $\$ 890$

$L B: \$ 845$

\section{Japan}

UB: $\$ 450$ | LB: $\$ 230$

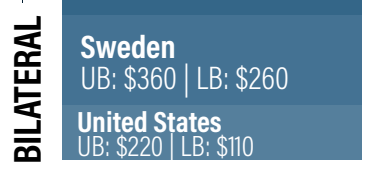

\section{Asian}

Development Bank

$\$ 1,580$

\section{EU Institutions \\ UB: $\$ 1,560$ \\ LB: $\$ 790$}

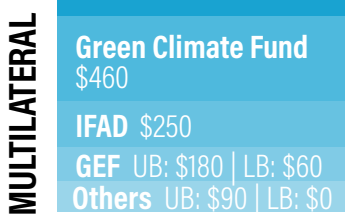

Others UB: $\$ 60$

$L B: \$ 30$
RECIPIENTS

Sub-Saharan Africa

UB: $\$ 2,880$

LB: $\$ 1,670$

South and Central Asia

UB: $\$ 1,740$

LB: $\$ 370$

Countries

UB: $\$ 1,420$

LB: $\$ 790$

East Asia and

the Pacific

UB: $\$ 1,140$

LB: $\$ 300$

Latin America and

the Caribbean

UB: $\$ 930$

LB: $\$ 520$

Europe UB: $\$ 320 \mid \mathrm{LB}: \$ 80$

MENA UB: $\$ 270$ | LB: \$30

\section{USES}

Agriculture

UB: $\$ 2,880$

LB: $\$ 950$

Other

UB: $\$ 1,480$

LB: $\$ 540$

General Environment

Protection

UB: $\$ 1,340$

LB: $\$ 730$

Biodiversity

UB: $\$ 980$

LB: $\$ 950$

Water

UB: $\$ 840$

LB: \$140

DRR

UB: $\$ 640$

LB: $\$ 20$

Forestry

UB: $\$ 550$

LB: $\$ 430$

Note: $\mathrm{UB}=$ Upper Bound, $\mathrm{LB}=$ Lower Bound

Source: Based on raw data from OECD.Stat database, Creditor Reporting System, modified by the authors. 


\subsection{Key Funding Modalities for NbSA}

For the three years analyzed, up to 85 percent of all tracked funding was categorized as ODA grants, and those that are categorized by the OECD as ODA loans are deemed "concessional," implying a significant grantequivalent component (see Table 2).

\subsection{Recipients and Uses of Funding}

\subsubsection{Recipients}

The top regions for tracked ODA funding for NbSA in 2018 were Sub-Saharan Africa, Latin America and the Caribbean, and South and Central Asia (see Table 3 and Figure 7). A large proportion of ODA funding does not specify the recipient country or region, indicating that significant amounts of funding flow through bilateral or multilateral multicountry programs (classified as going to "unspecified developing countries" by the OECD).

\subsubsection{Uses of Funding}

Biodiversity, general environmental protection, and agriculture are the top three NbSA-related sectors by estimated volume of funding tracked in 2018 (see Figure 8). ${ }^{11}$

For all of the graphs below, the solid line represents the upper bound, and the dashed line represents the corresponding lower bound.

\subsection{International Funding Channels}

The primary funding channels listed for NbSA (as for adaptation in general) include generalist and specialist multilateral climate funds and MDBs as well as NbSspecific facilities. It should be noted that the figures for a fund's "estimated amounts available" are for the entire fund and are thus indicative only; for some funds in Table 4, these estimated amounts are unlikely to be solely for NbSA. (Please see Table 4 for a listing with their modalities.)
Table 2 | Funding Modalities

\begin{tabular}{|l|c|c|c|}
\hline MODALITY & $\mathbf{2 0 1 2}(\mathbf{\%})$ & $\mathbf{2 0 1 5}(\mathbf{\%})$ & $\mathbf{2 0 1 8}(\mathbf{\%})$ \\
\hline ODA grants & $79-80$ & $64-65$ & $67-85$ \\
\hline ODA loans & $20-21$ & $29-34$ & $11-14$ \\
\hline Other $^{\mathrm{a}}$ & NA & $0-7$ & $1-22$ \\
\hline
\end{tabular}

Notes: $\mathrm{ODA}=$ official development assistance.

a. Includes other official flows (nonexport credit), equity investments, and private development finance (refers to philanthropies and nongovernmental organizations). Other official flows are defined as official sector transactions that do not meet ODA criteria, such as criteria for concessionality.

Source: Based on raw data from OECD.Stat database, Creditor Reporting System, modified by the authors.

Table 3 | Funding Received by Region and Country (US\$̦, millions)

\begin{tabular}{|c|c|c|c|}
\hline REGIONS & 2012 & 2015 & 2018 \\
\hline Sub-Saharan Africa & $370-900$ & $1,110-2,020$ & $1,670-2,880$ \\
\hline $\begin{array}{l}\text { Latin America and the } \\
\text { Caribbean }\end{array}$ & $490-630$ & $650-1,000$ & $510-930$ \\
\hline South and Central Asia & $260-590$ & $230-920$ & $370-1,740$ \\
\hline East Asia and the Pacific & $480-900$ & $230-750$ & $300-1,140$ \\
\hline Europe & $25-150$ & $45-390$ & $80-320$ \\
\hline $\begin{array}{l}\text { Middle East and North } \\
\text { Africa }\end{array}$ & $120-210$ & $170-280$ & $30-270$ \\
\hline $\begin{array}{l}\text { Unspecified developing } \\
\text { countries }\end{array}$ & $380-790$ & $240-870$ & $790-1,420$ \\
\hline
\end{tabular}

Source: Based on raw data from OECD.Stat database, Creditor Reporting System, modified by the authors.

See Appendix A for a breakdown of the regions by country. 
Figure 5 | Total ODA Funding Flows to NbSA

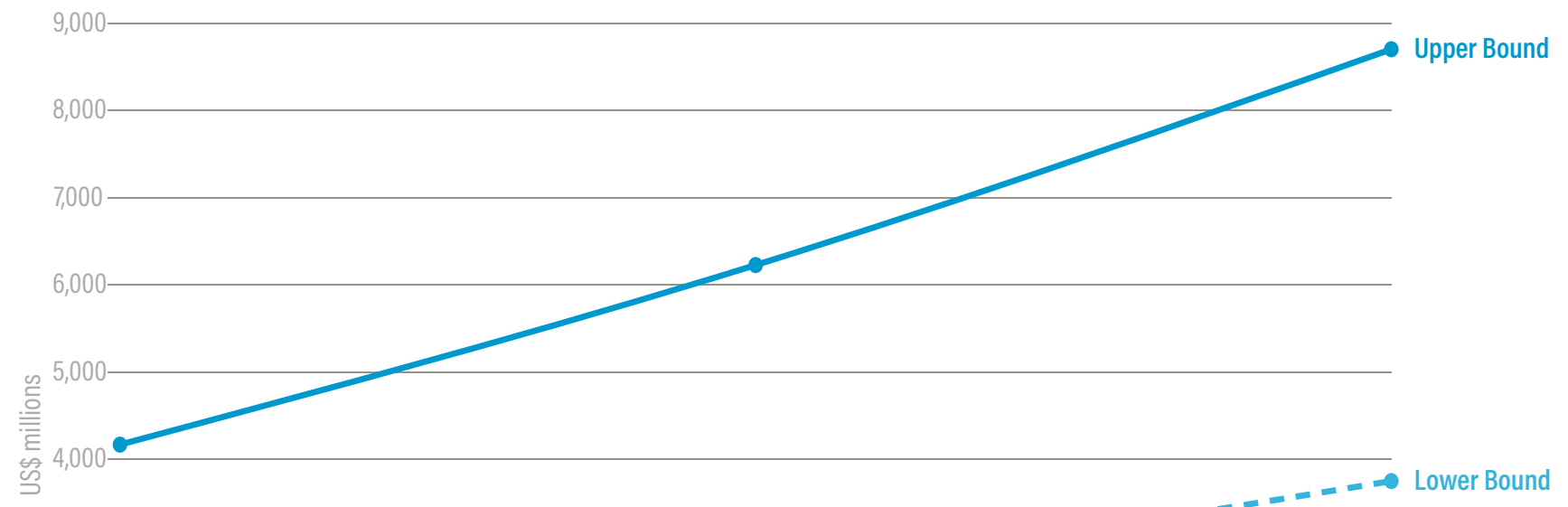

3,000

2,000

1,000

\begin{tabular}{lllllll}
\hline 2012 & 2013 & 2014 & 2015 & 2016 & 2017 & 2018
\end{tabular}

Figure 6 | ODA NbSA Funding Flows from Top Donors

$\mathrm{LB}=$ Lower Bound $\mid \mathrm{UB}=$ Upper Bound

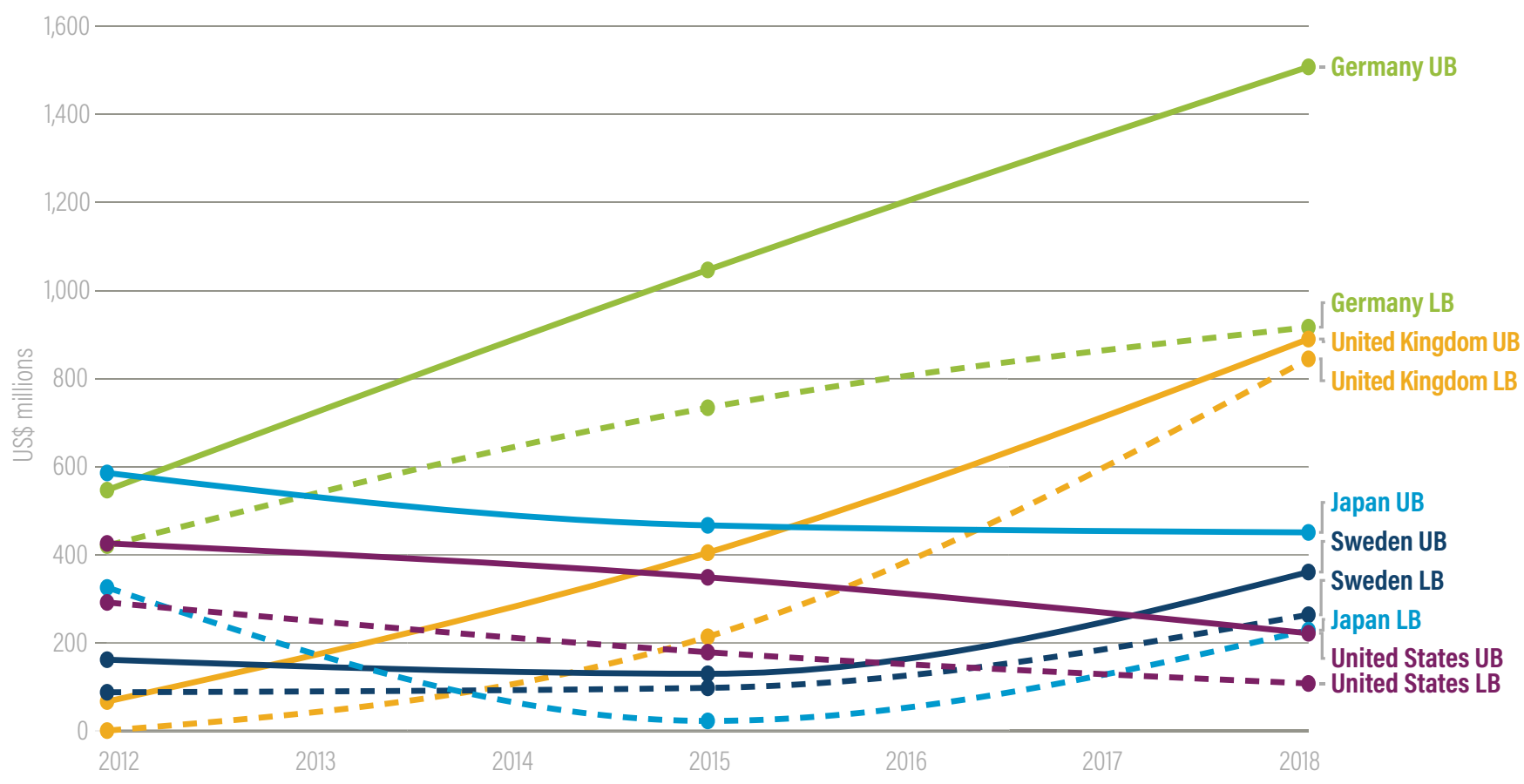


Figure 7 | ODA NbSA Funding Flows to Top Regions

$\mathrm{LB}=$ Lower Bound $\mid \mathrm{UB}=$ Upper Bound

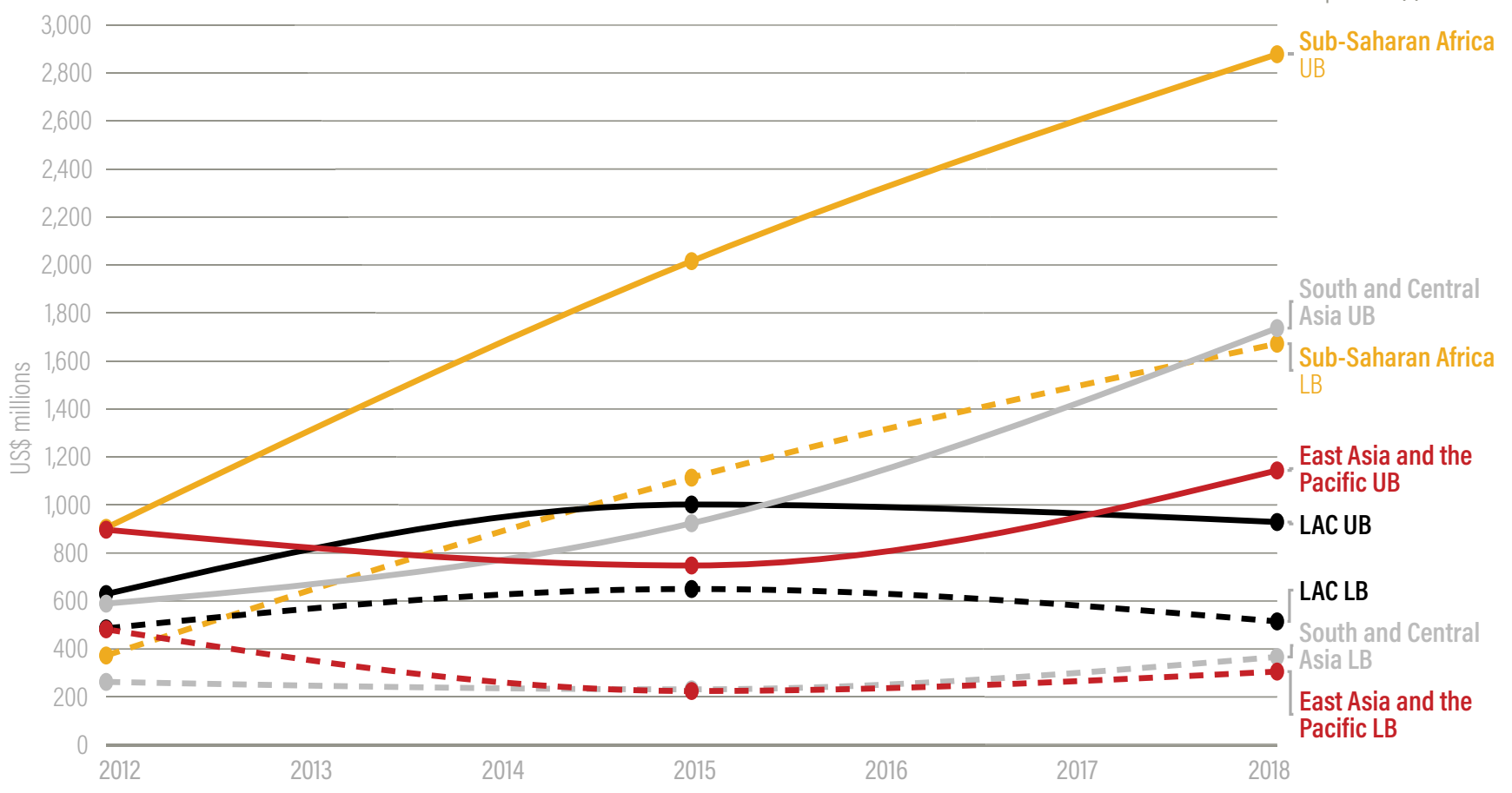

Figure 8 | ODA NbSA Funding Flows into Selected Sectors (Lower-Bound Only)

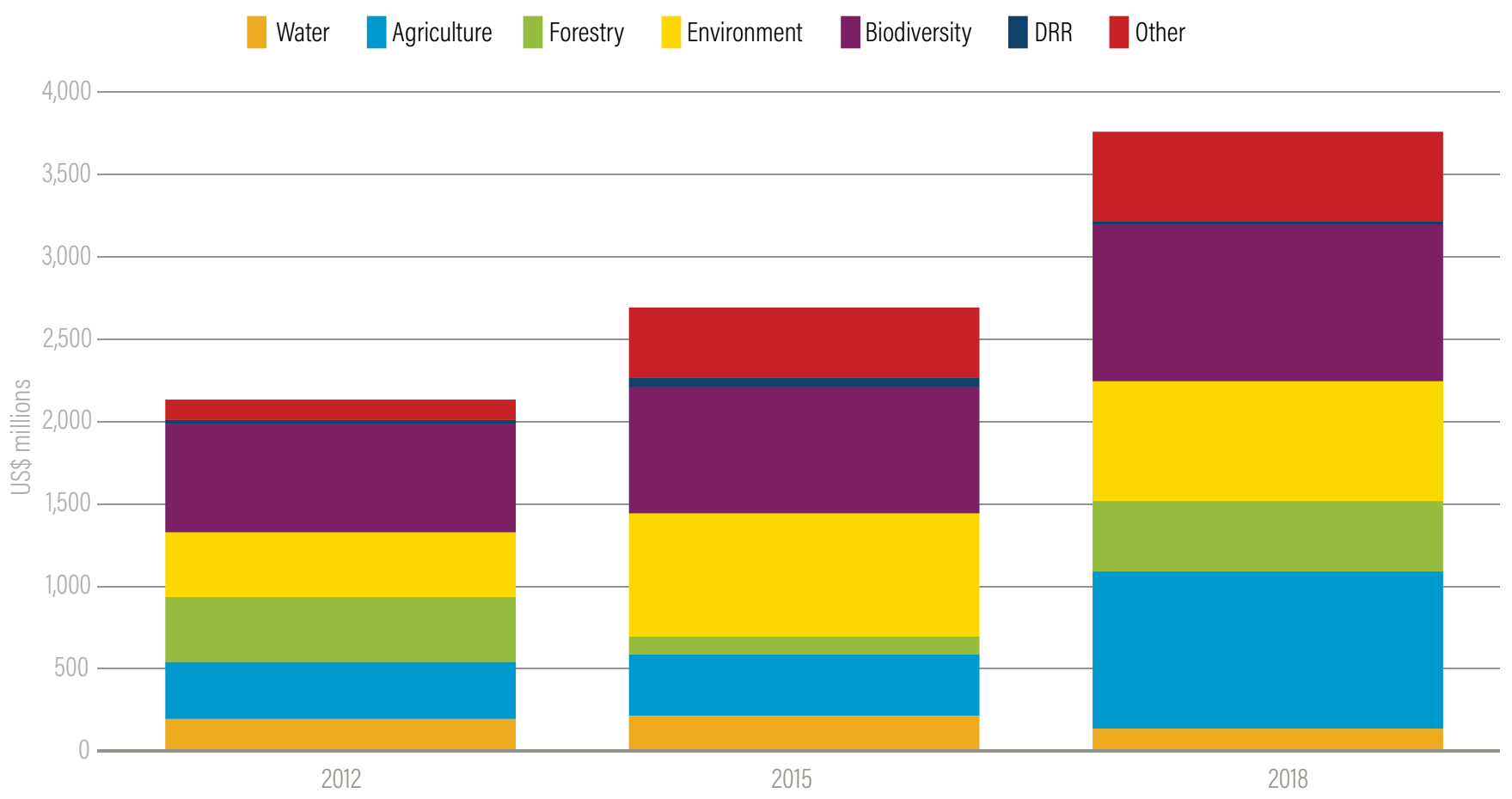

Notes: $\mathrm{DRR}=$ disaster risk reduction; $\mathrm{LAC}=$ Latin America and the Caribbean; $\mathrm{NbSA}=$ nature-based solutions for adaptation; ODA = official development assistance.

Source: Based on raw data from OECD.Stat database, Creditor Reporting System, modified by the authors. 


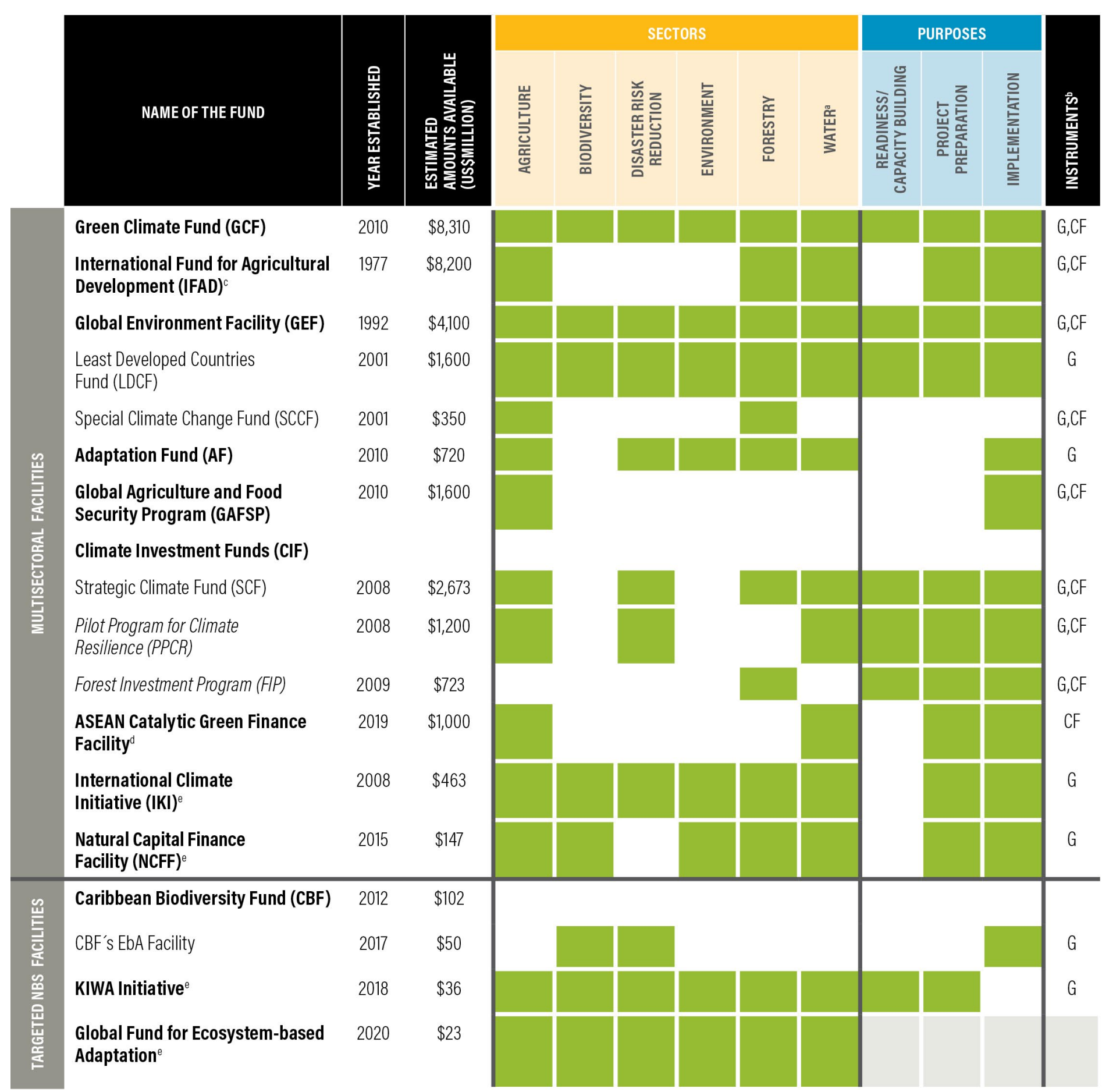

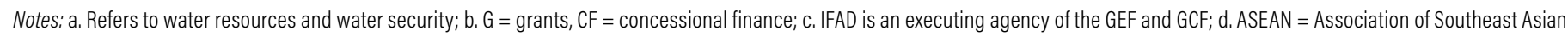
Nations; e. Using a euro to U.S. dollar conversion rate of 1:1.172.

Source: The authors. 


\section{BARRIERS AND CHALLENGES}

In a background paper for the Commission, the UNEP World Conservation Monitoring Centre identified several building blocks to underpin the widespread adoption of NbSA (see Figure 9):

Awareness and understanding of benefits among all stakeholders

- Knowledge and evidence base of the value and effectiveness of NbSA

Policy and regulatory support or a good enabling environment

Access to finance with sufficient volumes, from a wide range of sources, and in suitable types of financing instruments

Technical capacity among all stakeholders to develop, design, fund/finance, and implement NbSA
These building blocks are meant to illustrate key needs for scaling up NbSA, including the development of successful NbSA investments. This paper touches on three of these building blocks, each of which responds to specific but interconnected barriers: ${ }^{12}$

Barriers impeding awareness and understanding of NbSA benefits among stakeholders, which are driven by three key knowledge-related issues: the lack of definitions, data, and metrics.

Barriers preventing access to finance for NbSA with sufficient volumes, from a wide range of sources, and in suitable types of financing instruments.

The barriers and challenges listed in this section are derived from the sources listed in Box 2.

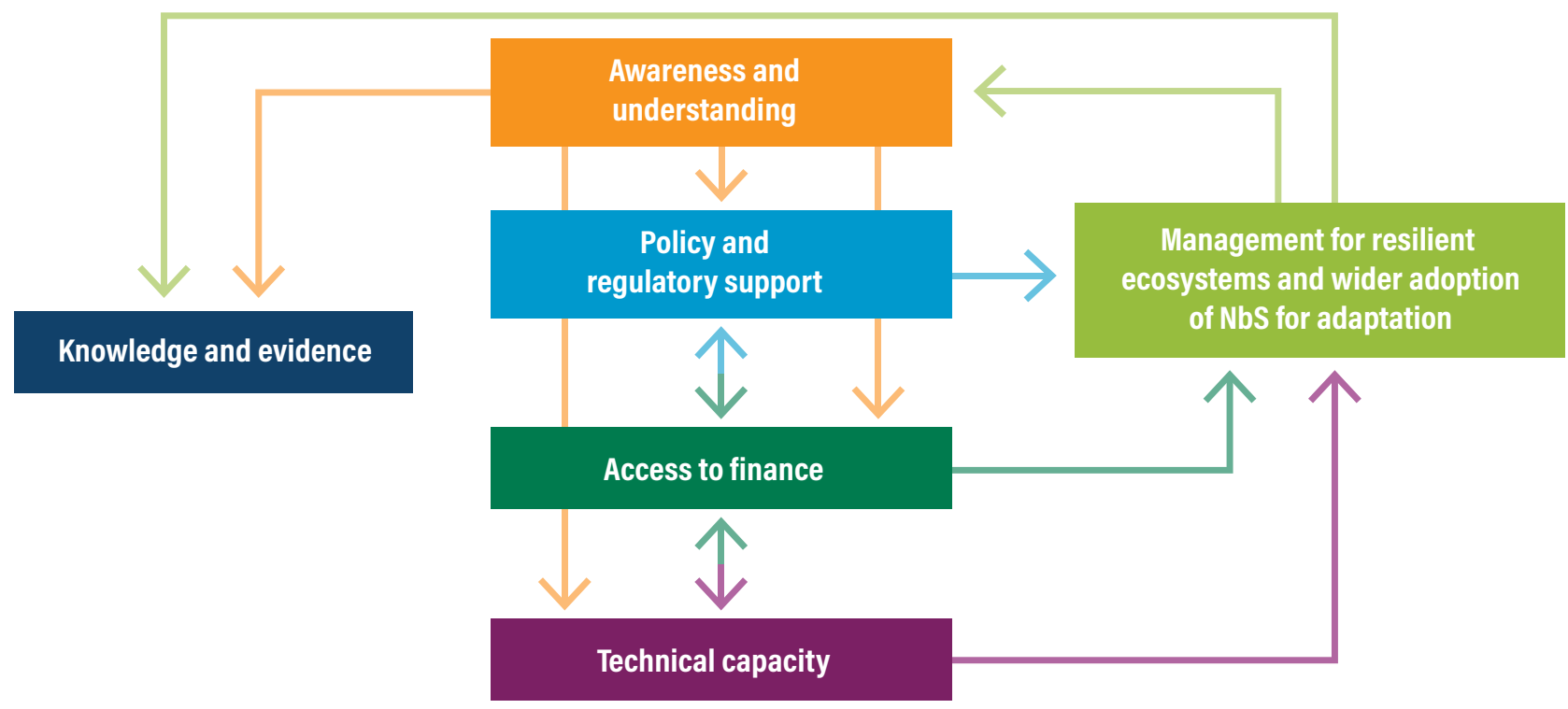

Note: $\mathrm{NbS}=$ nature-based solutions.

Source: Modified from Kapos et al. 2019. 


\subsection{Barriers Impeding Awareness and Understanding}

The lack of common definition, well-tagged information in the data sets, and clear metrics present significant overarching barriers to the adoption and scaling of NbSA (Figure 10). Interviewees consistently cited these issues, noting that they are interconnected and drive several other challenges related to NbSA financing.

\subsubsection{No Common Definition of NbSA Exists}

It was evident from the analysis of funding flows, and reinforced through interviews, that the definition of what qualifies as NbSA is unclear to many, suggesting that greater specificity and consistency is needed. One challenge is that project proponents often define such investments first and foremost by their core focus (e.g., biodiversity, water resources management) rather than in terms of adaptation outcomes. Box 1 lists several existing definitions of NbSA that may be helpful.

\subsubsection{Clear Data on Funding for NbSA Is Lacking}

Clarifying what qualifies as NbSA will help support better tagging and data collection, which in turn will improve the tracking of funding for NbSA (UNEP 2021). Without an NbSA tag in the existing databases, many projects that may contribute to adaptation outcomes are not counted. The methodology employed in this paper captures adaptation-related investments in specific sectors, but they may not be directly relevant to NbSA. The lack of a clear tag thus results in imperfect accounting, which makes it difficult to measure the amount of funding already flowing and to monitor its effectiveness, can make it difficult to fully meet the needs for NbSA and to raise additional funding (Somarakis et al. 2019).

\subsubsection{No Clear Metrics Exist to Value NbSA}

Although there are some systems, standards, and tools currently in development (see Box 5 in Section 5.3), as of now, no commonly agreed upon set of performance metrics to determine the impact of NbSA investments (individually or collectively) exists. The lack of commonly adopted metrics, as well as methodologies that can value the economic and financial benefits of these investments, has contributed to the inability of countries, project developers, and investors to appropriately appraise NbSA as an investment proposition against other options. These metrics and methodologies would enable project proponents to understand a range of important issues related to funding NbSA investments, such as life cycle operational costs and the values of adaptation benefits, which are important in developing approaches to mobilize additional capital.

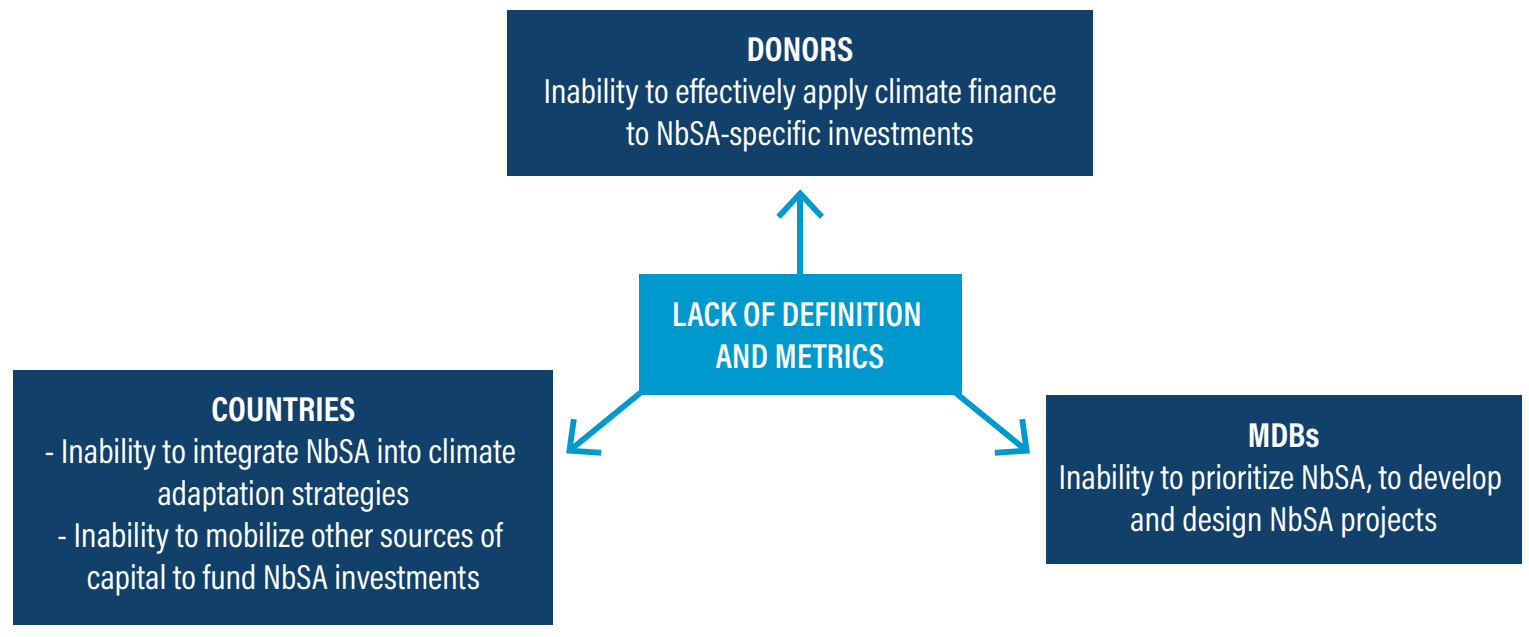

Note: $\mathrm{MDB}=$ multinational development bank; $\mathrm{NbS}$ = nature-based solutions.

Source: The authors. 


\subsection{Barriers Preventing Access to Finance}

Barriers identified in this section are specific to donor and other international (excluding domestic) public sources of funding-in particular, those barriers that impact the sources (donor funding), the channels (intermediaries and climate funds), and the uses (recipient countries). The following outlines key barriers at each of these points within the financing landscape.

\subsubsection{Donor Sources of Funding Are Insufficient in Volume}

There is clearly an overall funding gap for adaptation (at least $\$ 180$ billion per year needed, against approximately $\$ 30$ billion in current flows), of which NbSA is a piece; and an overall funding gap for NbS, of which NbSA is also a piece. As mentioned earlier, donor/ODA funding for NbSA accounts for only o.6-1.4 percent, or $\$ 3.8-\$ 8.7$ billion of total tracked climate finance flows, and a small portion of overall adaptation flows (tracked at $\$ 42$ billion).

\subsubsection{Donor Sources of Funding Do Not Align with Needs}

Donor funding is often provided in ways that may not meet the funding needs for NbSA investments in recipient countries. The assessment highlights the following specific barriers and challenges:

\section{Available funding and allocated funding do not explicitly identify NbSA as a focal area.} This results in poor understanding by recipients of where to access funding for NbSA and poor tracking of funding flows for NbSA. The lack of clarity means that donors may be less able to understand the current levels of support for NbSA investments and to assess the effectiveness of existing funding and efficiently allocate additional funding.

\section{Funding is predominantly grant-based and does not maximize options for catalyzing} NbSA investments. As previously noted, up to 80 percent of tracked funding was provided in the form of grants. Although grants are necessary and important-notably, to support capacity building, technical assistance, and project preparation-employing public capital in investment structures through both grant and nongrant instruments can allow for approaches that more effectively mobilize private investment.

\subsubsection{Channels of Donor Funding Do Not Explicitly Promote NbSA}

The channels of donor funding for climate action-and, by extension, NbSA-are key sources of information and funding for recipient countries. Although few funding channels explicitly promote NbSA investments, many large climate funds and multilateral agencies bundle $\mathrm{NbS}$ interventions under other adaptation-related sectors (e.g., disaster risk reduction or water), which can make it difficult to track NbSA investments. The following barriers prevent greater uptake of NbSA investments:

\section{Existing funding channels rarely promote NbSA as an explicit investment priority.} Interviewees highlighted that funding channels do not clearly and consistently promote consideration or prioritization of NbSA options during project development phases. They noted that while broader NbSA-related options were discussed, it could be difficult to make a case for NbSA given the lack of clear definitions, metrics to assess costs and benefits, and incentives to choose NbSA over other options; in addition, NbSA options were not always prioritized by developing countries. Funding channels thus miss an opportunity to signal to recipients the potential value of developing such projects, and they miss the opportunity to support them in developing such projects, thus limiting pipeline development.

\section{Funding modalities do not match funding} needs. Interviewees and research literature noted that for many NbSA investments, a mismatch exists between the modality of funding, either at the development stage (where primarily project development grants would be used) or at the investment stage, where a range of grant and investment instruments (e.g., debt, equity, results-based finance, etc.) could be useful (UNEP 2021). In particular, interviewees highlighted the need to support the relatively high operations and maintenance (O\&M) costs of NbS projects over their lifetimes, especially in circumstances where NbSA projects have insufficient revenue streams to bear those costs. 


\subsubsection{Challenges in Developing the NbSA Pipeline Hinder} Access to Financing

With more than 60 percent of all first NDCs including NbSA (Seddon et al. 2020b), there is clearly a latent demand for NbSA investment from developing countries. With the existing ambiguities around definitions and what "counts" as NbSA and the lack of clear signals within the system of funding (from both donors and channels), it is likely that the overall demand for NbSA investments is far greater than simply what exists within the collective NDCs today, yet the development of a pipeline that matches such demand is still lacking. The following is a list of barriers at the country level that prevent the development of a robust pipeline of NbSA investments in developing countries:

A general lack of awareness and understanding of NbS often exists among key stakeholders (Somarakis et al. 2019). Governments must understand not only the benefits of NbSA but also how to mainstream NbSA into climate and development plans and how to develop, value, and structure NbSA investments. This is further compounded by the barriers around awareness and understanding because key stakeholders may not understand the (emerging) evidence around the potential uses of $\mathrm{NbS}$; this is apparent, for instance, in how nonforest ecosystems are rarely included in NDCs (Seddon et al. 2019).

A lack of coordination between stakeholders can be problematic because $\mathrm{NbSA}$ require relevant expertise to appraise and value the cobenefits across sectors. Interviewees noted that NbS often necessitates coordination and collaboration horizontally (across government departments), vertically (from policymakers to local communities and other stakeholders), and across geographical regions. This is challenging and increases the risk of failure if not executed well. Furthermore, government agencies most knowledgeable about NbSA are rarely those that make key planning and budgeting decisions.
NbS are not prioritized among potential categories of adaptation investment, leading to more limited demand from developing countries (Egusquiza et al. 2019; Sarabi et al. 2020). Even when cited in NDCs and NAPs, NbS are often not prioritized in public budgets and investment plans. One reason for this is that government officials may feel pressure to deliver more immediate and tangible results, preferring familiar "gray" interventions that are easier to model in terms of benefits and are thus easier to structure from a funding perspective. Many interviewees noted that it was far easier to undertake a cost-benefit analysis for gray infrastructure projects than more comprehensive interventions like NbSA because of the lack of a common methodology for assessing the economic and financial benefits of NbSA and the cobenefits, even though NbSA can often be superior (Seddon et al. 2020a, 2020b).

It is difficult to prepare $\mathrm{NbS}$ investments, including assessing and internalizing the range of economic and financial benefits resulting from an NbS project (Global Commission on Adaptation 2019). Many developing countries have difficulty assessing, valuing, and structuring NbS investments as well as undertaking the necessary stakeholder engagement to ensure successful investment and implementation. 


\section{OPPORTUNITIES AND PROMISING}

\section{APPROACHES}

Several examples have been identified through both interviews and research that highlight ways to address these barriers and contribute to the building blocks needed for scaling up the implementation of NbSA. These promising approaches can provide useful lessons and insights to funders, channels of funding, and developing countries (see Figure 11).

\subsection{Policy and Regulatory Support}

\section{Mainstream NbSA to address adaptation}

priorities. Early identification and consideration of NbS options are essential to their implementation. Helping countries develop "green" and "gray/green" adaptation approaches alongside traditional "gray" solutions is a useful exercise; NbS approaches can be more cost-effective, have additional benefits (Seddon et al. 2020a, 2020b), and can also complement gray infrastructure by reducing risk, lowering operational and capital costs, and providing redundancy benefits (Browder et al. 2019).

\section{Engage local and international stakeholders} early in the process. The crosscutting nature of NbSA necessitates robust and coordinated stakeholder engagement, including the following actions:

Engaging local communities, indigenous title holders, and others to incorporate their perspectives.

Involving policymakers and decision-makers from across relevant ministries and levels of government.

Effectively coordinating donors to ensure funding is aligned with country needs and preferences.

Figure 11 | Four' Promising Approaches to Scale the Implementation of NbSA

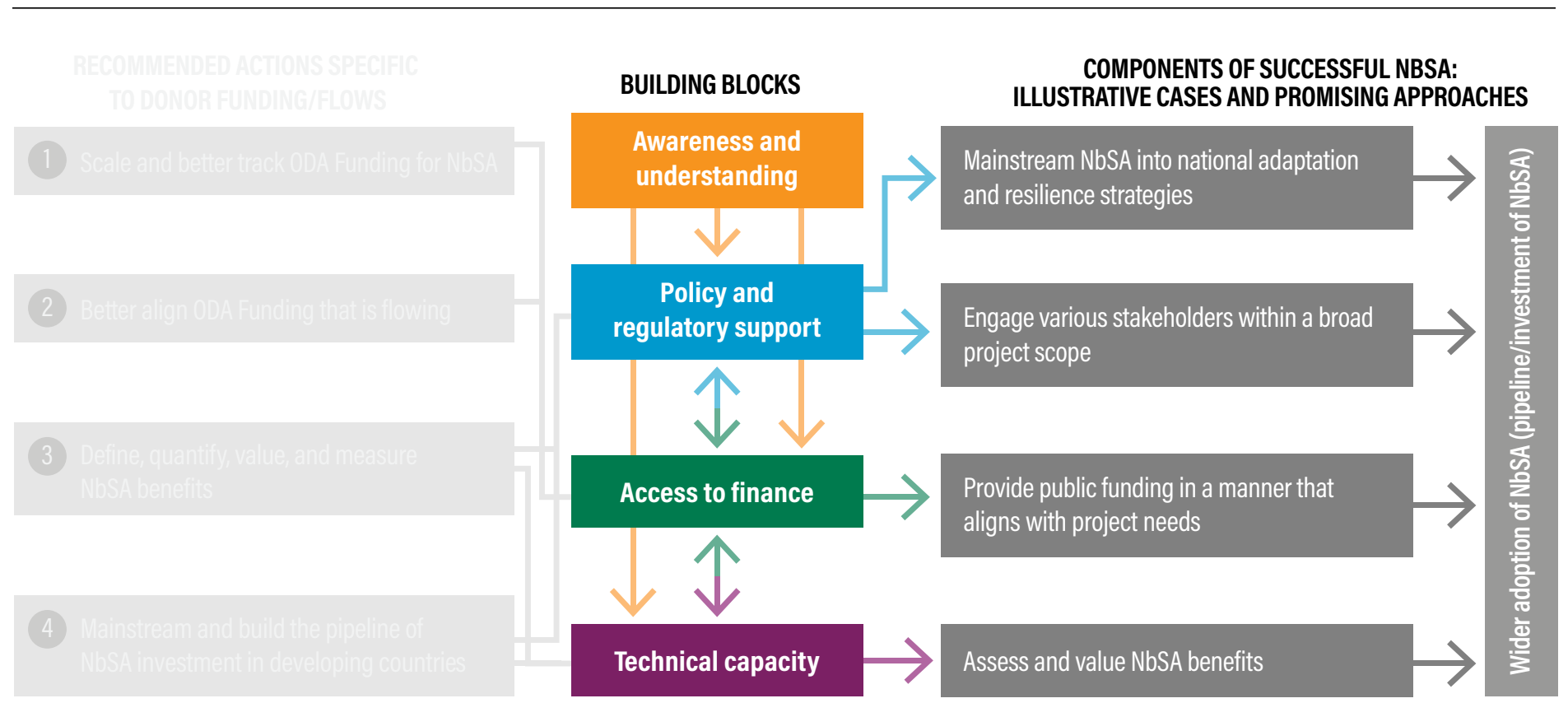

Note: $\mathrm{NbSA}$ = nature-based solutions for adaptation.

Source: Modified from Kapos et al. 2019. 


\subsection{Access to Finance}

\section{Provide public funding in a manner that aligns with project and/or investment needs. Interviewees noted the particularities of NbSA that may require different funding approaches than those employed for traditional "gray" solutions. These approaches include the following:}

The potential for results-based approaches (for example, payments for ecosystem services; see Appendix B for others) to deliver funding that has proved effective in catalyzing private investment.

The need to fund both capital expenditures (e.g., project development) and O\&M expenditures. Some NbSA projects have little or no revenue streams to cover ongoing O\&M costs, discouraging investment.

The potential use of public funding to anchor and/ or de-risk project finance structures and, where possible, the use of blended finance approaches to enable NbSA investment. ${ }^{13}$

\subsection{Technical Capacity}

Assess and value NbSA benefits. Given the gaps in knowledge about the economic, resilience, health, and other benefits of intact or restored ecosystems, NbSA options may be underappreciated by decision-makers, financiers, and beneficiaries. Resources are often needed to quantify value and measure outcomes.

Quantify value. Conduct quantified ex ante and ex post assessment/valuation and cost-benefit analysis to enable appropriate economic comparisons between NbSA and other investment options. This can help some stakeholders to recognize the systemic value that NbSA brings to different beneficiaries. See Box 5 in Section 5.3 for more details.

Measure outcomes. Track, monitor, and measure outcomes to strengthen the evidence base for the effectiveness and efficiency of NbSA. Coupled with strong valuation approaches, this will assist in building awareness and understanding of how NbS approaches (such as conservation and ecosystem restoration) can contribute to adaptation and other benefits.

The following examples illustrate how these promising approaches have been implemented. 


\section{Example 1 | Mangrove Restoration in Vietnam}

\begin{tabular}{ll}
\hline PUBLIC FUNDING MODALITY & Grant \\
\hline DATES & $1994-2010$ \\
\hline COUNTRY/REGION & Vietnam, South and Central Asia \\
\hline SECTOR & Infrastructure; food security and rural livelihoods \\
\hline HAZARDS ADDRESSED & Storm surge, flooding, sea level rise, drought \\
\hline AMOUNT OF PUBLIC FUNDING & $\$ 8.9$ million \\
\hline AMOUNT OF TOTAL FUNDING & $\$ 8.9$ million \\
\hline FUNDERS & Danish Red Cross, Japanese Red Cross \\
\hline COBENEFITS & $\begin{array}{l}\text { Carbon sequestration, nutrient retention, sediment retention, biodiversity habitat, flood attenuation, wastewater treatment, water } \\
\text { supply and recharge }\end{array}$
\end{tabular}

\section{BUILDING BLOCKS ADDRESSED}

Description: Afforestation with mangroves was considered an effective means to combat the loss of natural coastal protection by safeguarding sea dykes, reducing the risk of flooding, and protecting livelihoods. The project was implemented in eight coastal provinces in northern Vietnam from 1994 to 2010. Projects were implemented with the Vietnamese government's support and with efforts to involve local communities and stakeholders in the planning and development process; community ownership of the project was high. Capacity building was also an essential component of the project and included the training of local stakeholders and government officials. The project improved disaster preparedness for hundreds of communities, reduced extreme weather risks for millions of people, and had direct eco- nomic benefits to families in those communities. Savings due to avoided risks was approximately $\$ 15$ million, resulting in a cost-benefit ratio (including ecological benefits) of 1:60.

Relevance for scaling the adoption of NbSA: This example provides strong evidence of the importance of ensuring methodologies for measurements and reporting metrics are developed ex ante and underpin economic cost-benefit and impact analysis. It also illustrates the importance of stakeholder engagement in terms of how the activity depended on cooperation between international organizations, the national government, and community-level staff and volunteers. 


\section{Example 2 | Water Funds in Peru}

\begin{tabular}{lll}
\hline PUBLIC FUNDING MODALITY & Grant \\
\hline DATES & 2004-ongoing \\
\hline COUNTRY/REGION & Peru, Latin America and the Caribbean \\
\hline SECTOR & Water security and rural livelihoods \\
\hline HAZARDS ADDRESSED & Storm surge, flooding, sea level rise, drought \\
\hline AMOUNT OF PUBLIC FUNDING & $\$ 1.7$ million \\
\hline AMOUNT OF TOTAL FUNDING & $\$ 2$ million, plus annual payments by private stakeholders \\
\hline FUNDERS & DANIDA, DGIS, BMU, local private stakeholders, regional/local governments \\
\hline COBENEFITS & Nutrient retention, sediment retention, biodiversity habitat, flood attenuation, water treatment, water supply and recharge
\end{tabular}

\section{BUILDING BLOCKS ADDRESSED}

Policy and regulatory support

Access to finance

Technical capacity

Description: Three separate NbS interventions to improve watershed services in three regions in Peru were analyzed: engaging local communities to improve farming practices for better water capture, retention, use, and water flow; an appraisal of improved water management services and the consequent implementation of a payment for ecosystem services between watershed service providers and water users; and, through collaboration with local stakeholders and key private sector actors, the creation of a financial mechanism (Aquafondo) to generate public-private partnerships for investment in the three watersheds. Public finance was utilized for the initial implementation and launch of the projects; each of the three projects also includes financial mechanisms to incorporate private capital as payments for the continued water-related services generated and to ensure sustainable 0\&M.
Relevance for scaling the adoption of NbSA: The three interventions highlight the successful collaboration between national governments, international donors, nonprofit organizations, the private sector, and local communities to advance NbS for watershed management and adaptation and to implement sustainable financing mechanisms. These interventions also showcase the assessment and valuation of ecosystem services, which supported the successful monetization of improved sustainability measures on water resources, with water users providing payments to watershed service providers. 


\section{Example 3 | Debt-for-Nature Swaps in Seychelles}

\begin{tabular}{lll}
\hline PUBLIC FUNDING MODALITY & Grant, loan, sovereign debt discount \\
\hline DATES & $2011-15$ \\
\hline COUNTRY/REGION & Seychelles, Sub-Saharan Africa \\
\hline SECTOR & Food security, flood and coastal protection \\
\hline HAZARDS ADDRESSED & Sea level rise, ocean acidification, storm surge \\
\hline AMOUNT OF PUBLIC FUNDING & \$21.6 million \\
\hline AMOUNT OF TOTAL FUNDING & \$21.6 million \\
\hline FUNDERS & Belgium, France, Italy, the United Kingdom (under the Paris Club), The Nature Conservancy, various philanthropic organizations \\
\hline COBENEFITS & Habitat for fish species, biodiversity conservation, disaster risk reduction \\
\hline
\end{tabular}

\begin{tabular}{|l|c|c|}
\hline \multicolumn{2}{|c|}{ BUILDING BLOCKS ADDRESSED } \\
\hline Policy and regulatory support & Access to finance & Technical capacity \\
\hline
\end{tabular}

Description: The project aimed to sustainably finance and promote marine conservation efforts in Seychelles while easing the country's public debt burden. The Seychelles Conservation and Climate Adaptation Trust (SeyCCAT) was created to raise grant and loan capital for marine conservation. It purchased $\$ 21.6$ million of Seychelles' sovereign debt with $\$ 5$ million in grant funding (primarily from philanthropies), a $\$ 15.2$ million loan from The Nature Conservancy (TNC) repayable at 3 percent over 10 years, and a $\$ 1.4$ million discount on Seychelles' debt negotiated through the Paris Club (93.5 cents on the dollar). SeyCCAT committed over the next 20 years to disbursing $\$ 280,000$ per year for marine conservation and climate adaptation activities and investing $\$ 150,000$ per year in endowment to fund future conservation efforts.
Relevance for scaling the adoption of NbSA: This is an example of how public capital can be used to repurpose an existing expenditure stream into paying for conservation and adaptation instead of just paying down debt. It highlights all core building blocks: it identifies NbSA (a debt-for-nature swap to reduce sovereign debt while preserving natural capital and increasing resilience to climate impacts); assesses the impact of the intervention; and clearly engages international, national, and local stakeholders to secure permanent funding for both the initial capital and continued operational costs of the project. 


\section{Example 4 | Insuring Natural Capital-Coral Reef Insurance in Mexico}

\begin{tabular}{lll}
\hline PUBLIC FUNDING MODALITY & No data \\
\hline DATES & 2018-ongoing \\
\hline COUNTRY/REGION & Latin America and the Caribbean \\
\hline SECTOR & Disaster risk reduction, infrastructure \\
\hline HAZARDS ADDRESSED & Increasing temperatures, sea level rise, tropical cyclones \\
\hline AMOUNT OF PUBLIC FUNDING & \$3.8 million insurance cover \\
\hline AMOUNT OF TOTAL FUNDING & No data \\
\hline FUNDERS & SwisSRe, TNC, local/regional governments, local private stakeholders \\
\hline COBENEFITS & Habitat for fish species, biodiversity conservation \\
\hline
\end{tabular}

\begin{tabular}{|l|c|c|}
\hline \multicolumn{2}{|c|}{ BUILDING BLOCKS ADDRESSED } \\
\hline Policy and regulatory support & Access to finance & Technical capacity \\
\hline
\end{tabular}

Description: The Coastal Zone Management Trust was established by the state government of Quintana Roo in Mexico with the participation of Mexico's National Commission of Natural Protected Areas, TNC, and partners in the local science community and tourism industry to purchase an insurance-for-nature policy provided by SwissRe. The policy allows the trust to secure funding for ongoing maintenance and to quickly repair damages to the state's coral reef following a hurricane, preventing long-term damage and enhancing the protection of onshore communities. The project recently paid out $\$ 850,000$ to fund reef restoration after Hurricane Delta in October 2020.
Relevance for scaling the adoption of NbSA: The Coastal Zone Management Trust receives funds from an existing fee paid by beachfront property owners, among other private and public sources, to enable the community to advance communal NbS. This project highlights all building blocks: it clearly identifies NbS; assesses, values, and monetizes the natural capital in place; engages international and local stakeholders; and secures funding to protect and maintain the valuable natural asset. 


\section{RECOMMENDATIONS}

Public international sources of capital can help build the necessary foundations for the successful implementation and scaling up of NbSA, address critical barriers preventing all types of funding from flowing, and accelerate the development of an investment pipeline. The recommended actions described below (and in Figure 12) are aimed at two primary stakeholder groups:

Donors. Public international donors that provide ODA and climate finance for NbSA as well as some related technical assistance and capacity building.

Channels. Institutions like MDBs and international climate funds that are important channels of NbSA funding and can encourage countries to integrate NbSA into investment plans and undertake NbSA investments while helping them build the knowledge and capacity to do so.
Some of the recommendations also apply to developing countries insofar as those countries have a similar need to adopt definitions, metrics, and methodologies for NbSA and to develop and design fundable NbSA investments.

The recommended actions flow from the barriers identified in Section 3 and the promising approaches described in Section 4, which resulted from analysis of the data on funding flows as well as from interviews with key stakeholders, including donors, developing countries, and others. They also build on the Commission's Adapt Now report, focusing on specific recommendations for public international donor funding of ODA to support greater scale and effectiveness of NbSA. They are meant to complement recommendations from other recent reports, including those that focus on issues necessary to increase the mobilization of private capital for NbS more generally (see Box 4 for more details).
RECOMMENDED ACTIONS SPECIFIC TO DONOR FUNDING/FLOWS

\section{Scale and better track ODA funding for NbSA}

2 Better align ODA funding that is flowing

(3) Define, quantify, value, and measure NbSA benefits
Mainstream and build the pipeline of NbSA investment in developing countries
BUILDING BLOCKS

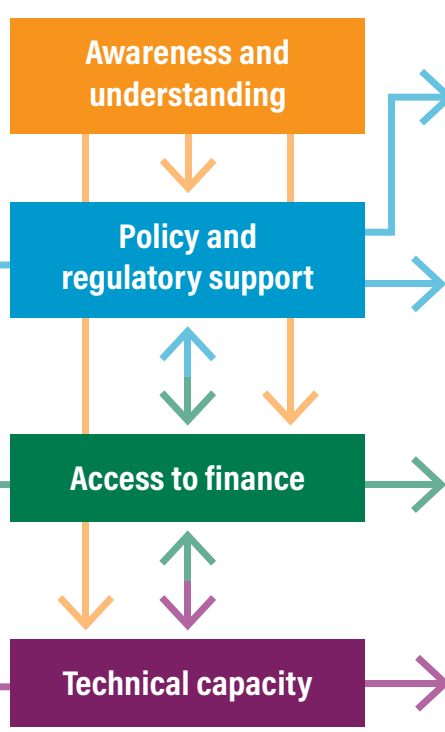

COMPONENTS OF SUCCESSFUL NBSA: ILLUSTRATIVE CASES AND PROMISING APPROACHES

Mainstream NbSA into national adaptation and resilience strategies

Engage various stakeholders within a broad project scope

Provide public funding in a manner that aligns with project needs

Assess and value NbSA benefits
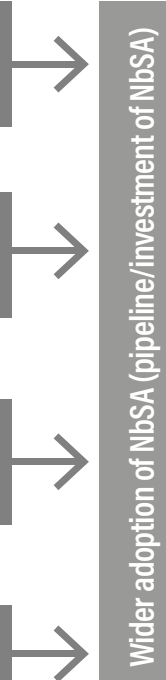

Notes: $\mathrm{NbSA}=$ nature-based solutions for adaptation; ODA = official development assistance.

Source: Modified from Kapos et al. 2019. 


\section{Box 4 | Recent Reports on Catalyzing Private Investment for Nature-based Solutions}

Several recent reports highlight initiatives and provide recommendations on increasing the mobilization of private capital for nature-based solutions (NbS). Below is a list of several reports with their key findings.

\begin{tabular}{l|l} 
REPORT & KEY FINDINGS \\
\hline
\end{tabular}

Inter-American Development Bank: Nature-Based Solutions: Increasing Private Sector Uptake for ClimateResilience Infrastructure in Latin America and the Caribbean ${ }^{\text {a }}$

Paulson Institute, The Nature Conservancy, and the Cornell Atkinson Center for Sustainability: Financing Nature: Closing the Global Biodiversity Financing Gap

World Bank: Mobilizing Private Finance for Naturec

TNC and Environmental Finance: Investing in Nature: Private Finance for Nature-based Resilience
- The financial sector should develop its own standards and good practices for incorporating biodiversity risk into investment decisions.

- Financial mechanisms need to be developed to increase the return or cash flow of investments.

- Raise awareness of NbS and enhance capacity to integrate NbS into decision-making within ministries responsible for planning, financing, and implementing infrastructure projects.

- Build capacity by providing tools and opportunities to develop technical skill sets.

- Stakeholders need to develop the business case to drive demand for financial products that can support NbS.

- Multilateral development banks can develop and deploy innovative instruments to finance and refinance NbS.

- Build capacity in assessing how investment decisions impact biodiversity; manage and disclose biodiversity risk.

- Develop robust evidence on the costs and performance of different forms of natural infrastructure.

- Develop internal policies and performance metrics that incentivize the structuring, offering, and use of financial products with explicit benefits to biodiversity.

- Value and measure: adopt natural capital accounting to keep track of stocks and flows.

- Structure: larger investment vehicles are urgently needed to enable investment at scale.

- Facilitate: greater awareness and understanding of the role of natural capital and of the profit opportunities it offers.

- Incentivize and regulate: financial industry regulators can provide guidance and help to manage the economic implications of biodiversity loss. 


\subsection{Action \#1: Scale and Better Track 0DA Funding for NbSA}

Given the likely significant funding gap between estimated flows and overall investment needs for NbSA, donors should prioritize and scale up their climate finance and ODA commitments for NbSA. The following is a list of actions specifically focused on how donors and channels of NbSA can scale and better track public international funding for $\mathrm{NbSA}$, with the involvement of developing countries.
ACTOR RECOMMENDED ACTIONS
Donors
- Define. Adopt common definitions of NbSA and apply the Rio markers more rigorously and consistently.
- Demand and promote better measurement. Ensure that channels of ODA for NbSA measure investments effectively.
- Accurately track NbSA investments, even when they are crosscutting with and/or embedded in other development impact areas or undertaken for a different primary purpose (such as biodiversity, forestry, or water management.
- Adopt consistent methodologies, such as the International Institute for Sustainable Development's Sustainable Asset Valuation (SAVi) tool, to enable greater measurement of cobenefits as well as impacts and successes from NbSA.
- Allocate more climate finance/ODA for NbSA.
- Increase allocations to MDBs and multilateral climate funds and/or specific dedicated NbS funding mechanisms, particularly those that can deploy capital most efficiently and with speed, particularly to meet latent and future demands for NbSA.
- Actively monitor results. Ensure that channels for NbSA and broader NbS funding
- integrate indicators for NbSA cobenefits within monitoring and evaluating (M\&E) frameworks; and
- monitor and track NbSA results, including as part of crosscutting interventions.

MDBs/

international

climate funds and

other channels
- Prioritize and identify NbSA. Support and engage in the ongoing development of emerging criteria and standards for NbSA best practices ${ }_{1}^{14}$ and apply them to support the identification of promising NbSA projects in the pipeline.

- Actively monitor results. Ensure that countries specifically:

- integrate indicators for NbSA cobenefits within M\&E frameworks; and

- monitor and track NbSA results, including as part of crosscutting interventions.

- Prioritize and identify NbSA. Work with donors, MDBs, and civil society on the development of criteria and standards for NbSA best practices and apply them to support the identification of promising NbSA projects that are aligned with national climate plans (e.g., NDCs and NAPs). 


\subsection{Action \#2: Better Align 0DA Funding That Is Flowing}

Public international funding for NbSA is primarily provided in the form of grants. ${ }^{15}$ Although important, this reliance on grants may limit opportunities to catalyze other forms of capital for NbSA, including by using concessional finance to crowd in private capital. Interviewees noted two potential additional ways that public international funding can be useful for NbSA projects:

Grants for long-term O\&M costs. Interviewees noted potential mismatches between funding available for capital costs and the need for NbSA to cover longer-term O\&M costs. This mismatch is particularly challenging for projects with low or no revenue streams to cover these costs. Lack of visibility on how these O\&M costs are covered can be decisive in investment decisions.
Concessional and nongrant instruments. Utilizing public international funding through nongrant instruments (e.g., guarantees, concessional debt, and equity) to help crowd in private capital is common among many climate-related sectors. Many interviewees suggested that innovative approaches to catalyze private investment in NbSA would benefit from greater access to public international funding.

The following actions specifically focus on how donors and channels of NbSA, as well as developing countries, can better align public international funding for $\mathrm{NbSA}$ project needs.

Donors

- Broaden (funding) support. Provide guidance on risk tolerance and authorize funding channels, where possible, to use funding in both grant and nongrant investment instruments to support

- all relevant costs, including long-term project costs, such as 0\&M costs; and

- taking greater risk/higher risk tolerance in order to crowd in private investment.

- Coordinate and align. Improve the coordination among donors and donor-led initiatives to ensure NbSA-related funding is aligned with country needs, especially through the early engagement of national and local stakeholders.

MDBs/ international climate funds and other channels
- Align with country needs. Ensure support provided to developing countries is aligned with national plans and budgets and promote the mainstreaming of NbSA to address adaptation needs.

- Facilitate NbSA project planning. Given the crosscutting nature of NbSA, help countries coordinate NbSA project planning and development among agencies. Ensure the early engagement of local communities, relevant ministries, and other stakeholders and levels of government as appropriate.

- Mobilize. Actively employ blended finance approaches to leverage, crowd in, and otherwise mobilize private and philanthropic capital into NbSA investments. (See examples in Appendix B.)

- Broaden (funding) support. Ensure instruments that address funding and financing gaps in NbSA projects, including those that employ results-based financing approaches, allow for payment of both capital expenditures and 0\&M costs.

- Build capacity. Fully fund, through grants, important technical assistance, awareness and knowledge, capacity building, and project development efforts.

Developing countries
- Be strategic with, and maximize the impact of, ODA received to accelerate NbSA investments. Take a strategic view on how best to utilize ODA and other public funding to accelerate NbSA investment, including employing approaches to blend public capital that mobilize private capital for eligible projects where feasible. 


\subsection{Action \#3: Define, Quantify, Value, and Measure NbSA Benefits}

The absence of clear definitions, guidelines, and metrics and methodologies to track, quantify, and value $\mathrm{NbSA}$ benefits may contribute to the relative scarcity of the right types of capital (both grant and nongrant/investment capital), which in turn may significantly inhibit the development of a robust pipeline of NbSA-related investments by public and private sectors.

Thus, the single most important technical gap that, if addressed, may facilitate greater $\mathrm{NbS}$ financing is the need to develop, adopt, and accelerate a common approach to define, quantify, value, and measure NbSA benefits in ways that are meaningful for investment decision-making, including quantifying (economic and financial) values for NbSA outcomes for public and private investors and countries. Such a framework (e.g., monitoring, reporting, and verification [MRV] for NbSA) will be foundational to increase evidence and awareness, shift planning and policy, and stimulate pipeline development and financing for NbSA; thus, it is a critical component for scaling up these types of investments.

Several efforts are attempting to develop methodologies for quantifying NbS benefits (see Box 5), including for adaptation. The following table provides recommendations for how donors and channels, as well as developing countries, can support the development of these approaches and accelerate their adoption.

\section{Donors - Value/quantify. Fund the development and adoption of approaches (e.g., MRV for NbSA) that articulate metrics and quantify avoided costs and/or the value of protecting nature, including those that build financial modeling capacity within both public and private investors. \\ - Fund/support the expedited development, adoption, and application of the Task Force on Nature-related Financial Disclosures approach to quantifying nature-related financial risks (or others), which can help public and private investors integrate financial measures into structuring decisions.}

\section{MDBs/ international climate funds and other channels}

- Employ methodologies that quantify NbSA benefits for

- public stakeholders, including developing country governments that often need to quantify costs and benefits in economic development terms over long time horizons; and

- private investors, including lenders and others whose funds may be mobilized and who often need to quantify financial returns of their investments over shorter time horizons relevant for their investment approaches and return expectations.

Developing countries
- Engage and adopt. Work with donors, MDBs, and civil society on the development of useful and relevant methodologies for quantifying NbSA benefits, testing and piloting best practices and frameworks where appropriate. Adopt these methodologies, when possible, to inform project/pipeline development, continuing to build the evidence base for NbSA. 


\section{Box 5 | Examples of Standards, Tools, Metrics, and Valuation Methodologies for Nature-based Solutions}

\section{Task Force on Nature-related Financial Disclosures (2021)}

Composed of several international financial institutions and governments, this initiative aims to develop a framework to assess, quantify, and disclose nature-related financial risks. Currently still an informal working group, this initiative is expected to launch in the first half of 2021.

\section{Natural Capital Finance Alliance (NCFA), Exploring Natural Capital Opportunities, Risks and Exposure (ENCORE) (2018)}

A tool that aims to help financial institutions in their understanding, assessment, and integration of natural capital considerations into their decision-making. ENCORE provides information to allow portfolio screening and the management of natural capital risks and opportunities. ${ }^{2}$

\section{Coalition for Private Investment in Conservation (CPIC), Blueprints (2018)}

CPIC, which is a global multistakeholder group composed of investors, banks, project developers, nongovernmental organizations, and research institutions, has developed a series of "blueprints" of model financial transaction structures that aim to facilitate the replication and scaling of investments that deliver both economic and conservation returns. ${ }^{b}$

\section{International Institute for Sustainable Development (IISD), Sustainable Asset Valuation (SAVi) tool: Natural Infrastructure (2019)}

Together with the MAVA Foundation, the IISD developed the SAVi methodology to assist policymakers and investors in making informed infrastructure financing decisions. The methodology takes into account environmental, social, economic, and governance factors across the full life cycle of the project. SAVi not only considers the economic, social, and environmental risks and their associated costs to the financial performance of the project but also identifies and captures externalities that may not be reflected in traditional valuation methods.

A recently launched Global Environment Facility project aims to systematically and rigorously assess the economic and financial value of nature-based infrastructure. It will strengthen the IISD SAVi tool to integrate climate change adaptation by using a systems-based financial modeling and integrating climate data from the Copernicus Climate Data Store. The resulting data and valuation models will then be disseminated to build capacity and technical knowledge.

Notes: a. See NCFA's ENCORE website, https://encore.naturalcapital.finance/en; b. Note that although CPIC does not explicitly focus on nature-based solutions for adaptation, conservation can bring mitigation and adaptation benefits as well.

Sources: Bassi et al. 2019, 2020; Cooper and Trémolet 2019; CPIC n.d. 


\subsection{Action \#4: Mainstream and Build the Pipeline of NbSA Investment in Developing Countries}

There is clearly latent demand for NbSA funding given the number of countries including such projects in their NDCs and NAPs. However, whether those projects can be realized and whether countries are expanding the application of NbSA to address adaptation needs is unclear. Funding should help countries develop and strengthen NbSA concepts to make them a reality and build a pipeline of new and additional NbSA investments. The following table provides suggestions for how both donors and channels can target grant funding for critical capacity building-both at the national and subnational levels-to increase the pipeline of NbSA investments.

\section{ACTOR RECOMMENDED ACTIONS \\ Donors - Build capacity. Ensure sufficient funding for technical assistance and capacity building efforts for all countries and project developers to design NbSA investments. \\ MDBs/ international climate funds and other channels \\ - Help countries mainstream NbSA. By leveraging existing tools and technical assistance support, expand the resources and support available to help countries to mainstream NbSA, including \\ - at the national level, into existing country strategies and plans related to adaptation and development, including post-COVID recovery plans; and \\ - at the subnational level, into infrastructure investments being made by municipalities and local communities, where appropriate. \\ - Develop explicit capacity building programs to \\ - help developing countries integrate NbSA into NDCs and adaptation policies and plans; \\ - provide project preparation funding and technical assistance to help countries and subnational entities design NbSA projects, including technical design, impact analysis, and valuation of NbSA benefits (economic and financial); and \\ - provide specific support to help countries and subnational entities develop the financial structuring and investor proposition for NbSA, including life cycle analysis and operating costs.}

- Provide grants and technical support for countries and subnational entities to ensure comprehensive stakeholder engagement for NbSA investments.

Developing countries
- Strengthen the mainstreaming of NbSA to meet climate adaptation objectives, especially through the integration of NbS and NbSA in updates to country NDCs, NAPs, and other "green economy" or climate-related planning.

- Work with donors, MDBs, and other funding channels to develop a tangible pipeline of NbSA investments, moving from conceptualization to design, structuring, and implementation. 


\section{CONCLUSION}

The results of this research show there is a long way to go to improve overall flows for NbSA and, in turn, to see NbSA investments realized and implemented in developing countries. Although the funding landscape shows low levels of funding today, donor and country interest in NbSA has accelerated rapidly in recent years. It is likely that future assessments will paint a different picture, including where funding is flowing from and which countries and regions are receiving support.

Research and interviews have highlighted how much work is needed to define and quantify NbSA at the project investment level, and there is growing interest across the donor and multilateral development community to invest in the necessary methods, tools, and approaches that can support scaling up NbSA investment. It is widely accepted that investments in NbSA support public goods that enhance the ability of countries and communities to adapt to climate change and to better withstand disasters when they occur.

For developing countries where domestic budgets may be constrained, an immediate and important opportunity exists to integrate $\mathrm{NbS}$ investments (writ large) into post-COVID economic recovery planning to reap a range of immediate and long-term climate resilience benefits. Furthermore, doing so has the potential to bring about a more robust (and resilient) post-COVID recovery, increase economic growth, create jobs, and yield other long-term positive development impacts.
Today, public capital is often still a decisive factor in determining whether an NbSA project is implemented and its benefits realized. Investing in NbSA at scale will require both greater investment levels from public and private sources and, importantly, improved coordination among many stakeholders, including developing country policymakers and planners, project developers, and communities, all of whom have diverse interests and incentives. This coordination is key, in part because the crosscutting nature of NbSA can make such interventions more complex. The need to build the capacity of all of these stakeholders to develop investable NbSA project pipelines cannot be overstated.

This paper's recommended actions provide an initial road map that can help each of these stakeholders build the right systems, approaches, and tools to enable the scaling up of NbSA investments while maximizing both the effectiveness of donor funding for NbSA and the ability of developing countries to become resilient in the face of climate change. 


\section{APPENDIX A: METHODOLOGY}

This paper seeks to estimate donor funding for NbSA through traditional development assistance channels. Estimates are based on the OECD's CRS database, which tracks ODA and nonconcessional development finance flows. These include the bilateral outflows provided by donors, primarily the OECD's Development Assistance Committee (DAC) members, and plurilateral/ multilateral fund and institution outflows to recipient countries.

CRS projects are classified by sector. Donors and donor agencies tag some of these projects with the Rio markers, which indicate either the primary or significant intent of the funding, such as mitigation, adaptation, or biodiversity. Sector classifications are exclusive-a funding flow cannot be tagged with more than one sector. Markers are not exclusive-funding flows can be tagged with more than one marker.

The authors used the following methodology to estimate total NbSA flows:

- A list of sectors was selected that encompasses likely NbS projects (see Table A1 for the full list of sectors).

- Projects were filtered from these sectors, counting those marked with both adaptation and biodiversity markers to produce a lower-bound estimate.

- Projects tagged as adaptation only were used to produce an upper-bound estimate.

- Committed flows for NbSA were then calculated for 2012, 2015, and 2018 (the most recent year available).

The lower-bound estimates do not include funding from and through multilateral channels, such as MDBs or climate funds, given how multilateral data is reported to the $0 \mathrm{ECD}$.
When reporting climate finance data, additional coefficients are sometimes applied to discount projects marked as significant versus those marked principal. For example, some donors report 100 percent of the commitment for projects marked as principal, while a smaller share (varying between 0 percent and 100 percent) is reported for significant flows (OECD n.d.). Following the practice of these donors, 100 percent of amounts for flows marked principal have been reported, whereas a coefficient of 50 percent was applied to flows marked significant.

In summary, the upper and lower bounds were constructed as follows:

- Lower bound:

- Projects marked with both adaptation and biodiversity Rio markers.

- All reported at 100 percent unless both markers are significant, in which case the project value is discounted 50 percent.

- Upper bound: The upper bound encompasses the lower bound as a baseline; in addition, the following flows were added:

- Projects marked as having either a principal or significant focus on adaptation and no focus on biodiversity.

- Projects marked principal were reported at 100 percent.

- Projects marked significant were reported at 50 percent.

These bounds are summarized in Figure A1.

Without a clear definition or marker for NbS writ large, this methodology can only estimate flows toward projects that are likely related to NbSA; thus, all flows derived are not necessarily representative of actual flows for NbSA projects.

Figure A1 | Summary of Reporting Coefficients for Upper-/Lower-Bound Analysis

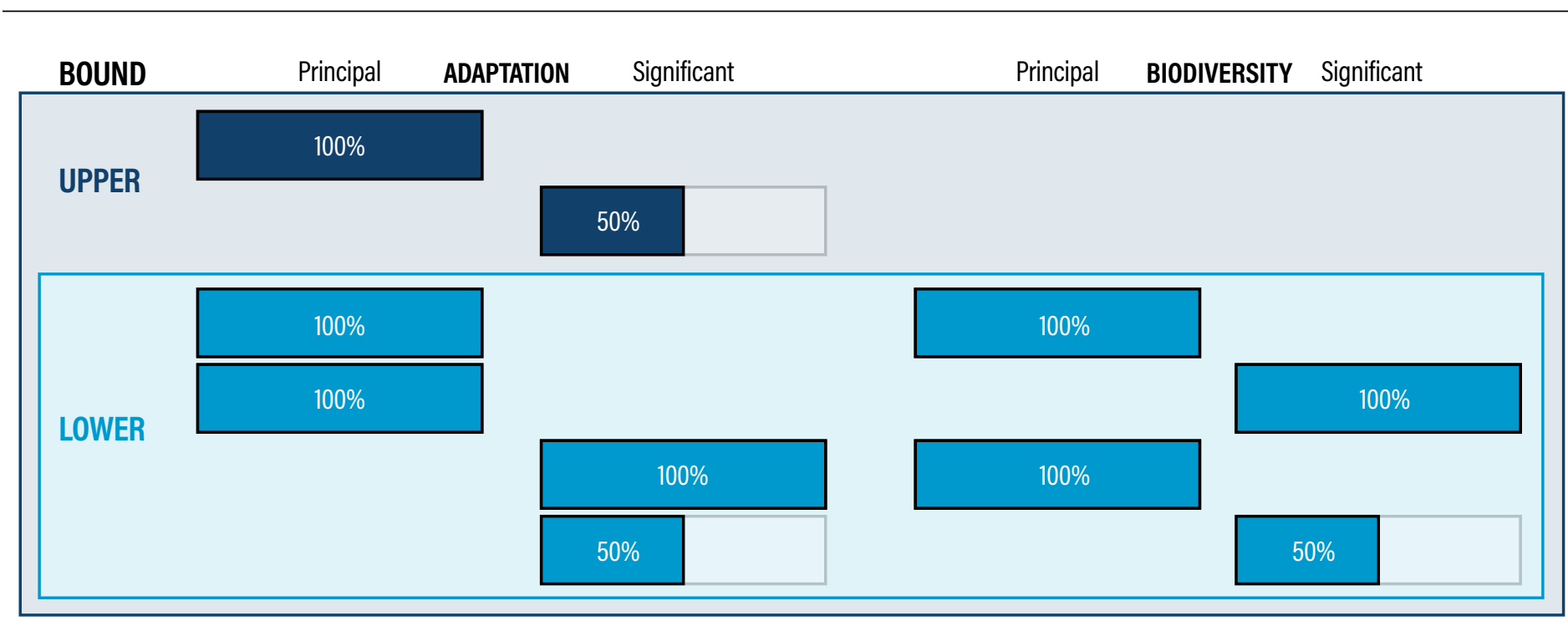

Source: Climate Finance Advisors. 
Table A1 | List of OECD DAC CRS Sector Codes Included

\begin{tabular}{|c|c|c|c|c|}
\hline DAC 5 & $\begin{array}{l}\text { CRS } \\
\text { CODE }\end{array}$ & $\begin{array}{l}\text { VOLUNTARY } \\
\text { CODE }\end{array}$ & DESCRIPTION & CLARIFICATIONS/ADDITIONAL NOTES ON COVERAGE \\
\hline 140 & & & $\begin{array}{l}\text { WATER SUPPLY \& } \\
\text { SANITATION }\end{array}$ & \\
\hline & 14010 & & $\begin{array}{l}\text { Water sector policy } \\
\text { and administrative } \\
\text { management }\end{array}$ & $\begin{array}{l}\text { Water sector policy and governance, including legislation, regulation, planning, and } \\
\text { management as well as transboundary management of water; institutional capacity } \\
\text { development; activities supporting the Integrated Water Resource Management approach. }\end{array}$ \\
\hline & 14015 & & $\begin{array}{l}\text { Water resources } \\
\text { conservation } \\
\text { (including data } \\
\text { collection) }\end{array}$ & $\begin{array}{l}\text { Collection and usage of quantitative and qualitative data on water resources; creation } \\
\text { and sharing of water knowledge; conservation and rehabilitation of inland surface waters } \\
\text { (rivers, lakes etc.), groundwater, and coastal waters; prevention of water contamination. }\end{array}$ \\
\hline & 14040 & & $\begin{array}{l}\text { River basins } \\
\text { development }\end{array}$ & $\begin{array}{l}\text { Infrastructure-focused integrated river basin projects and related institutional activities; } \\
\text { river flow control; dams and reservoirs (excluding dams primarily for irrigation [31140] and } \\
\text { hydropower [23220] and activities related to river transport [21040]). }\end{array}$ \\
\hline 310 & & & $\begin{array}{l}\text { AGRICULTURE, } \\
\text { FORESTRY, FISHING }\end{array}$ & \\
\hline 311 & & & AGRICULTURE & \\
\hline & 31110 & & $\begin{array}{l}\text { Agricultural policy } \\
\text { and administrative } \\
\text { management }\end{array}$ & $\begin{array}{l}\text { Agricultural sector policy, planning, and programs; aid to agricultural ministries; institution } \\
\text { capacity building and advice; unspecified agriculture. }\end{array}$ \\
\hline & 31120 & & $\begin{array}{l}\text { Agricultural } \\
\text { development }\end{array}$ & Integrated projects; farm development. \\
\hline & 31130 & & $\begin{array}{l}\text { Agricultural land } \\
\text { resources }\end{array}$ & $\begin{array}{l}\text { Including soil degradation control; soil improvement; drainage of water-logged areas; soil } \\
\text { desalination; agricultural land surveys; land reclamation; erosion control, desertification } \\
\text { control. }\end{array}$ \\
\hline & 31140 & & $\begin{array}{l}\text { Agricultural water } \\
\text { resources }\end{array}$ & Irrigation, reservoirs, hydraulic structures, ground water exploitation for agricultural use. \\
\hline 312 & & & FORESTRY & \\
\hline & 31210 & & $\begin{array}{l}\text { Forestry policy } \\
\text { and administrative } \\
\text { management }\end{array}$ & $\begin{array}{l}\text { Forestry sector policy, planning, and programs; institution capacity building and advice; } \\
\text { forest surveys; unspecified forestry and agroforestry activities. }\end{array}$ \\
\hline & 31220 & & $\begin{array}{l}\text { Forestry } \\
\text { development }\end{array}$ & $\begin{array}{l}\text { Afforestation for industrial and rural consumption; exploitation and utilization; erosion } \\
\text { control, desertification control; integrated forestry projects. }\end{array}$ \\
\hline & 31261 & & Fuelwood/charcoal & $\begin{array}{l}\text { Sustainable forestry development with the primary purpose of producing fuelwood and } \\
\text { charcoal. Further transformation of biomass in biofuels is coded under } 32173 .\end{array}$ \\
\hline & 31281 & & $\begin{array}{l}\text { Forestry education/ } \\
\text { training }\end{array}$ & \\
\hline & 31282 & & Forestry research & $\begin{array}{l}\text { Including artificial regeneration, genetic improvement, production methods, fertilizer, } \\
\text { harvesting. }\end{array}$ \\
\hline
\end{tabular}




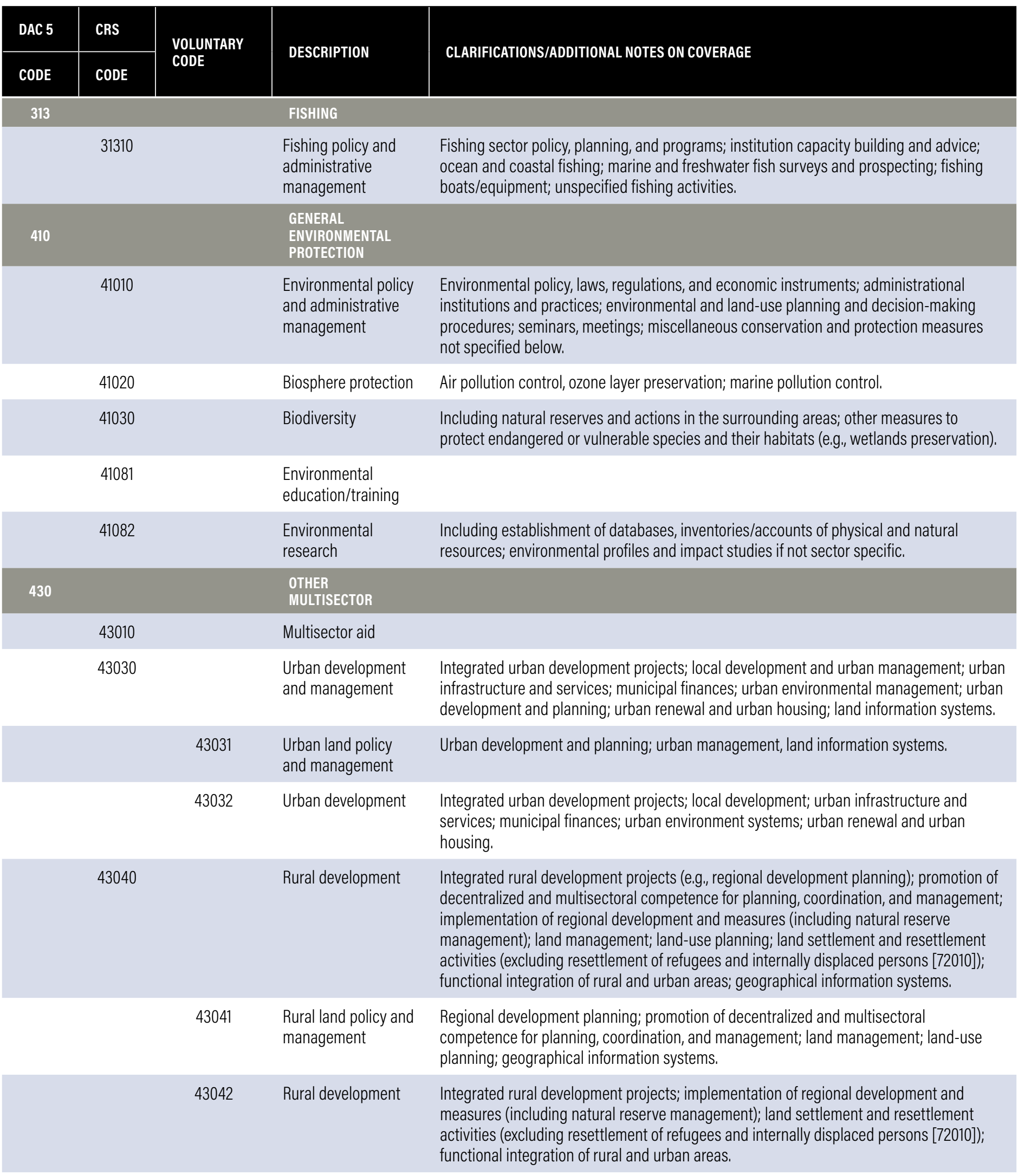


Table A1 | List of OECD DAC CRS Sector Codes Included (Cont:)

\begin{tabular}{|c|c|c|c|c|}
\hline DAC 5 & $\begin{array}{l}\text { CRS } \\
\text { CODE }\end{array}$ & $\begin{array}{l}\text { VOLUNTARY } \\
\text { CODE }\end{array}$ & DESCRIPTION & CLARIFICATIONS/ADDITIONAL NOTES ON COVERAGE \\
\hline & 43060 & & $\begin{array}{l}\text { Disaster risk } \\
\text { reduction }\end{array}$ & $\begin{array}{l}\text { Disaster risk reduction activities if not sector specific. Comprises risk assessments, } \\
\text { structural prevention measures (e.g., flood prevention infrastructure), preparedness } \\
\text { measures (e.g., early warning systems), normative prevention measures (e.g., building } \\
\text { codes, land-use planning), and risk transfer systems (e.g., insurance schemes, risk funds), } \\
\text { Also includes building local and national capacities and supporting the establishment of } \\
\text { efficient and sustainable national structures able to promote disaster risk reduction. }\end{array}$ \\
\hline & 43071 & & $\begin{array}{l}\text { Food security policy } \\
\text { and administrative } \\
\text { management }\end{array}$ & $\begin{array}{l}\text { Food security policy, programs, and activities; institution capacity strengthening; policies, } \\
\text { programs for the reduction of food loss/waste; food security information systems, data } \\
\text { collection, statistics, analysis, tools, methods; coordination and governance mechanisms; } \\
\text { other unspecified food security activities. }\end{array}$ \\
\hline & 43072 & & $\begin{array}{l}\text { Household food } \\
\text { security programs }\end{array}$ & $\begin{array}{l}\text { Short- or longer-term household food security programs and activities that improve the } \\
\text { access of households to nutritionally adequate diets (excluding any cash transfers within } \\
\text { broader social welfare programs that do not have a specific food security, food acquisition, } \\
\text { or nutrition focus, which should be reported under code 16010). }\end{array}$ \\
\hline & 43082 & & $\begin{array}{l}\text { Research/scientific } \\
\text { institutions }\end{array}$ & When sector cannot be identified. \\
\hline
\end{tabular}




\section{REGIONS}

Sub-Saharan Africa

Latin America and

Caribbean

South and Central Asia

East Asia and the Pacific

\section{OECD REGIONS AND COUNTRIES INCLUDED}

Africa, regional; South of Sahara, regional; Angola; Benin; Botswana; Burkina Faso; Burundi; Cabo Verde; Cameroon; Central African Republic; Chad; Comoros; Congo; Côte d'Ivoire; Democratic Republic of the Congo; Djibouti; Equatorial Guinea; Eritrea; Eswatini; Ethiopia; Gabon; Gambia; Ghana; Guinea; Guinea-Bissau; Kenya; Lesotho; Liberia; Madagascar; Malawi; Mali; Mauritania; Mauritius; Mozambique; Namibia; Niger; Nigeria; Rwanda; Saint Helena; São Tomé and Principe; Senegal; Sierra Leone; Somalia; South Africa; South Sudan; Sudan; Tanzania; Togo; Uganda; Zambia; Zimbabwe

America, regional; Caribbean, regional; Caribbean \& Central America, regional; South America, regional; Antigua and Barbuda; Argentina; Belize; Bolivia; Brazil; Colombia; Costa Rica; Cuba; Dominica; Dominican Republic; Ecuador; El Salvador; Grenada; Guatemala; Guyana; Haiti; Honduras; Jamaica; Mexico; Montserrat; Nicaragua; Panama; Paraguay; Peru; Saint Lucia; Saint Vincent and the Grenadines; Suriname; Venezuela

Asia, regional; Central Asia, regional; South \& Central Asia, regional; South Asia, regional; Afghanistan; Armenia; Azerbaijan; Bangladesh; Bhutan; Georgia; India; Kazakhstan; Kyrgyzstan; Maldives; Myanmar; Nepal; Pakistan; Sri Lanka; Tajikistan; Turkmenistan; Uzbekistan

Far East Asia, regional; Oceania, regional; Cambodia; China (People's Republic of); Cook Islands; Democratic People's Republic of Korea; Fiji; Indonesia; Kiribati; Lao People's Democratic Republic; Malaysia; Marshall Islands; Micronesia; Mongolia; Nauru; Niue; Palau; Papua New Guinea; Philippines; Samoa; Solomon Islands; Thailand; Timor-Leste; Tokelau; Tonga; Tuvalu; Vanuatu; Vietnam; Wallis and Futuna

Europe Europe, regional; Albania; Belarus; Bosnia and Herzegovina; Kosovo; Moldova; Montenegro; North Macedonia; Serbia; states of the former Yugoslavia, unspecified; Turkey; Ukraine

Middle East and North Africa
Middle East, regional; North of Sahara, regional; Algeria; Egypt; Iran; Iraq; Jordan; Lebanon; Morocco; Syrian Arab Republic; Tunisia; West Bank and Gaza Strip; Yemen 


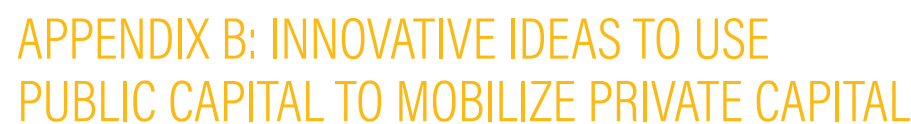

The following is a list of innovative ways to use public capital to mobilize private capital for NbSA as suggested by those interviewed for this paper and through our literature review.

Results-based finance (RBF): Mechanisms by which funds are disbursed when specific results are met after independent verification. Results-based climate finance would thus refer to RBF for specific climate change mitigation or adaptation objectives. A 2017 report by the World Bank indicated that results-based payments are well suited for mitigation projects because greenhouse gas (GHG) emissions are well-defined and measurable (WBG and Frankfurt School of Finance and Management 2017). The same report also noted the potential for results-based payment projects for adaptation. Some examples of RBF are listed below.

- Payments for ecosystem services: Direct or indirect transactions between the providers and beneficiaries of ecosystem services. In Section 4, this concept is represented by Example 2 for Peru (GEF 2014).

- "Feebate" concept for forestry: Fees for firms with emissions rates above a baseline level and subsidies for those with emissions rates below the baseline level. A 2019 paper by the International Monetary Fund (IMF) assessed feebate (tax subsidy) schemes as a potential fiscal instrument to promote GHG mitigation through forest carbon storage (IMF 2019).

- Monetizing water savings: Monetizes the efficient use of water in a "pay for performance" scheme, similar to how an energy service company monetizes the efficient use of energy (Global Innovation Lab for Climate Finance 2020).

\section{Green bonds and other types of debt:}

- Green bonds: Bonds issued to raise finance for environment- and climate-related projects, which can be printed by various issuer types, including governments, financial institutions, and nonfinancial corporates. In 2019, the Dutch government issued almost $\$ 7$ billion worth of bonds for low-carbon development and sustainable water management, with plans to specifically incorporate NbS (Almeida 2020; Anderson et al. 2019).
- Climate impact bond: Merges the idea of RBF with bonds, where an investor provides upfront capital to a service provider to deliver the targeted climate resilience outcome. Upon achievement of results, the outcome funder (typically a public sector agency or government) repays the investor at a premium (Puri and Khan 2019).

- Debt-for-nature swaps: A portion of a (developing) country's foreign debt is forgiven in exchange for investments in environmental protection and/or conservation. See Example 3 (Seychelles).

- Carbon offsets and taxes: In some countries and regions, revenues from carbon pricing/taxes are deposited into a fund (or otherwise earmarked) to further reduce carbon emissions and GHGs. For instance, California's Cap-and-Trade Program deposits its revenues into the state's Greenhouse Gas Reduction Fund (California ARB n.d.). However, research by the IMF indicates that only 15 percent of the world's carbon tax revenues have been used for environmental purposes. It is possible that these funds could begin to include adaptation (and NbSA) among their objectives. Carbon offsets could provide some of the revenue streams necessary to finance NbSA projects, though this would require scaling and strengthening of the global carbon markets.

Others:

- Parametric insurance for natural capital: A service provided by nature or an ecosystem is commodified, assigned a value, and insured. See Example 4 on coral reef insurance in Mexico.

- Restoration Insurance Service Company: Combines both the risk reduction value of natural capital with revenue from the trading of carbon credits (Global Innovation Lab for Climate Finance 2019). 
ABBREVIATIONS

BMU

CBD

CFA

CPI

CPIC

CRS

DAC

DANIDA

DGIS

DRR

EbA

ECo-DRR

ENCORE

GCF

GEF

GHG

GIZ

IDB

IFAD

IISD

IMF
Federal Ministry of Environment, Nature Conservation and Nuclear Safety of Germany

Convention on Biological Diversity

Climate Finance Advisors

Climate Policy Initiative

Coalition for Private Investment in Conservation

Creditor Reporting System

Development Assistance Committee

Danish International Development Agency

Directorate-General for International Cooperation

disaster risk reduction

ecosystem-based adaptation

Ecosystem-based disaster risk reduction

Exploring Natural Capital Opportunities, Risks

and Exposure

Green Climate Fund

Global Environment Facility

greenhouse gas

Deutsche Gesellschaft für Internationale

Zusammenarbeit

Inter-American Development Bank

International Fund for Agricultural Development

International Institute for Sustainable Development

International Monetary Fund
IUCN

LAC

M\&E

MDB

MRV

NAP

NbS

NbSA

NCFA

NDC

NORAD

0\&M

ODA

OECD

RBF

SAVi

SeyCCAT

TNC

UNDP

UNEP

UNFCCC

WRI
International Union for Conservation of Nature

Latin America and the Caribbean

monitoring and evaluating

multilateral development bank

monitoring, reporting, and verification

national adaptation plan

nature-based solutions

nature-based solutions for adaptation

Natural Capital Finance Alliance

nationally determined contribution

Norwegian Agency for Development Cooperation

operations and maintenance

official development assistance

Organisation for Economic Co-operation and Development

results-based finance

Sustainable Asset Valuation

Seychelles Conservation and Climate Adaptation Trust

The Nature Conservancy

United Nations Development Programme

United Nations Environment Programme

United Nations Framework Convention on Climate Change

World Resources Institute 
GLOSSARY

Biodiversity: The variability among living organisms from all sources, including, inter alia, terrestrial, marine, and other aquatic ecosystems and the ecological complexes of which they are part; this includes diversity within species, between species, and of ecosystems (CBD n.d.).

Donor: For the purposes of this paper, donor refers to organizations and institutions that primarily provide international assistance and support. In most cases, this includes national governments and multilateral development agencies, but in some cases, it may also include international/national NGOs or philanthropic foundations.

Ecosystem: The dynamic complex of plant, animal, and microorganism communities and their nonliving environment interacting as a functional unit (CBD n.d.),

Ecosystem-based adaptation (EbA): The use of biodiversity and ecosystem services as part of an overall adaptation strategy to help people adapt to the adverse effects of climate change. EbA aims to maintain and increase the resilience and reduce the vulnerability of ecosystems and people in the face of the adverse effects of climate change (SCBD 2009).

Ecosystem-based disaster risk reduction (Eco-DRR): "The sustainable management, conservation and restoration of ecosystems to reduce disaster risk, with the aim to achieve sustainable and resilient development" (Estrella and Saalismaa 2013).
Ecosystem services: The benefits people obtain from ecosystems, which the Millennium Ecosystem Assessment has classified as including provisioning services, such as the supply of food, fiber, timber, and water; regulating services, such as carbon sequestration, climate regulation, water regulation and filtration, and pest control; cultural services, such as recreational experiences, educational, and spiritual enrichment; and supporting services, such as seed dispersal and soil formation (Millennium Ecosystem Assessment 2005).

Gray infrastructure: Involves human-built and human-engineered assets that provide one or multiple services required by society, such as dams, levees, reservoirs, treatment systems, and pipes (Browder et al. 2019).

Natural capital: Natural assets such as forests, water, fish stocks, minerals, biodiversity, and land. It is from this natural capital that humans derive a wide range of services, often called ecosystem services, which make human life possible (World Forum on Natural Capital n.d.).

Natural infrastructure: Refers to land networks or ecosystems that provide services inherent to those geographical areas while also perpetuating active conservation efforts and the enhancement of those environments (Bassi et al. 2019).

Recipient: An organization or country that primarily receives funding and implements projects domestically. In most cases, it refers to developing countries that receive funding, but in some cases, it may also include organizations or institutions that receive funding and implement/manage projects. 
1. This assessment of official development assistance (ODA) and climate finance funding flowing for nature-based solutions for adaptation (NbSA) tracks funds committed in 2018. It does not assess domestic public financing or private investment as these data are difficult to obtain and, where available, are widely inconsistent. It may not capture all ODA that supports adaptation investments or investments that have adaptation cobenefits but are tagged as "mitigation" investments. Donors and funding channels listed are not exhaustive but represent the more significant contributors as identified for the relevant year.

2. This assessment focuses specifically on the use of NbSA outcomes, including ecosystem-based adaptation (EbA) along with EbA disaster risk reduction (DRR). Together, these cover the use of biodiversity and ecosystem services as part of an overall strategy to help people adapt to climate change as well as the sustainable management, conservation, and restoration of ecosystems to reduce disaster risk. Collectively, this paper labels these activities as NbSA.

3. NbSA was estimated to account for 5.8-13.5 percent of total public climate finance flows to developing countries in 2018 (which totaled $\$ 64.3$ billion) (OECD 2020a).

4. Includes both adaptation-specific flows and flows that have dual adaptation and mitigation benefits (Buchner et al. 2019).

5. Reliable estimates for total financing needs for NbSA (specifically) are not available.

6. Such as environmental policy, laws, regulations, and economic instruments; site preservation; and environmental research.

7. Forty-two percent refer to ecosystem-based adaptation actions, 20 percent to traditional conservation.

8. Since $2012, \mathrm{CPI}$ has tracked overall climate finance flows, including those for mitigation and adaptation. Although CPI tracks overall adaptation flows as well as flows for "agriculture, forestry, land-use and natural resource management," neither provides a clear picture of funding flowing for NbSA. CPI data shows that approximately 3 percent of overall climate finance flows are in the agriculture, forestry, land-use, and natural resource management category, but this also includes mitigation-focused investments. In both CPI's tracking and in this assessment, the lack of explicit definitions and tags in the ODA databases, inconsistencies in definitions, and reporting challenges may result in underestimated figures.
9. Referring to both adaptation-specific flows and flows that have dual adaptation and mitigation benefits in the CPI's Global Landscape of Climate Finance 2019 (Buchner et al. 2019).

10. The scale of GEF investment in NbSA, and NbS writ large, over the past 30 years is substantial, and there are also relevant funds coming through the Adaptation Fund and the Pilot Program for Climate Resilience. Some multilateral delivery channels may not be reporting consistently within the OECD databases (and/or may not report to the OECD at all); thus, this data may not fully capture their contributions to NbSA.

11. For details and descriptions of the sectors, please see Table A.1 in Appendix A.

12. Because this paper focuses on public international donor sources of funding for NbSA and the channels for those funds, the barriers covered in this section relate most closely to the building blocks on "knowledge," "awareness," and "financing." Although other building blocks are also important, the recommended actions have focused on "policy/regulatory" and "technical capacity" because donors fund actions related to those building blocks.

13. Such as guarantees to attract more risk-averse investment capital.

14. For example, the International Union for Conservation of Nature has been leading the development of a global standard for NbS writ large, and Deutsche Gesellschaft für Internationale Zusammenarbeit (GIZ) supported the development of a framework for defining criteria and standards for NbSA in 2018 (see FEBA 2017).

15. This paper primarily focuses on making ODA and public sources of capital for NbSA more effective and efficient. Innovative approaches for mobilizing private capital are illustrated in Appendix B. 
Adams, J. 2018, "There Is a Forgotten Solution to Climate Change That We Must Invest In-Nature." World Economic Forum, August 30. https://www. weforum.org/agenda/2018/08/investing-in-a-forgotten-solution-to-climatechange-nature/.

Adaptation Fund. n.d. "About the Adaptation Fund." https://www.adaptation-fund.org/about/. Accessed November 4, 2020.

ADB (Asian Development Bank). 2019. ASEAN Catalytic Green Finance Facility, Mandaluyong, Philippines: ADB. https://www.adb.org/sites/default/files/ publication/544486/asean-catalytic-green-finance-facility.pdf.

ADB. n.d. "Overview: ASEAN Catalytic Green Finance Facility (ACGF)," https:// www.adb.org/what-we-do/funds/asean-catalytic-green-finance-facility/ overview. Accessed November 4, 2020.

AFD (Agence Française de Développement). 2020. Kiwa Initiative Brochure. Paris: AFD. https://www.afd.fr/en/ressources/kiwa-initiative.

Almeida, M. 2020. Global Green Bond State of the Market 2019. London: Climate Bonds Initiative. https://www.climatebonds.net/system/tdf/reports/ cbi_sotm_2019_vol1_04d.pdf?file=1\&type $=$ node $\&$ id $=47577 \&$ force $=0$.

Anderson, J., T. Gartner, A. Mauroner, and J. Matthews. 2019. "Conservation Finance Takes Off as the Netherlands Issues One of the Largest Green Bonds Ever." Insights (blog), June 21. https://www.wri.org/blog/2019/06/conservation-finance-takes-netherlands-issues-one-largest-green-bonds-ever.

Bassi, A., L. Casier, G. Pallaske, 0. Perera, and R. Bechau. 2020. Sustainable Asset Valuation (SAVi) of Senegal's Saloum Delta: An Economic Valuation of the Contribution of the Saloum Delta to Sustainable Development, Focussing on Wetlands and Mangroves. Winnipeg, Canada: International Institute for Sustainable Development. https://www.iisd.org/system/files/2020-08/savi-saloum-delta-senegal.pdf.

Bassi, A., G. Pallaske, L. Wuennenberg, L. Graces, and L. Silber. 2019. Sustainable Asset Valuation Tool: Natural Infrastructure. Winnipeg, Canada: International Institute for Sustainable Development. https://www.iisd.org/system/ files/publications/sustainable-asset-valuation-tool-natural-infrastructure. pdf.

BIOFIN (Biodiversity Finance Initiative). 2017. Rwanda Biodiversity Expenditure Review. Kigali, Rwanda: United Nations Development Programme. https:// www.biodiversityfinance.net/sites/default/files/content/knowledge_products/Biodiversity\%20Expenditure\%20Review\%20Final\%20report.pdf.
BIOFIN. 2018a. Seychelles Public and Private Biodiversity Expenditure Review. Port Louis, Mauritius: United Nations Development Programme. https://www. biodiversityfinance.net/sites/default/files/content/knowledge_products/ BIOFIN\%20BER\%20March\%202018.pdf.

BIOFIN. 2018b. Viet Nam Biodiversity Expenditure Review. Hanoi: United Nations Development Programme Viet Nam. https://www.biodiversityfinance.net/sites/default/files/content/knowledge_products/Viet\%20Nam\%20 BER\%20report_0.pdf.

Blarel, B., G. Ruta, O. Gavryliuk, P. Poisson, F. Stewart, S. Power, B. Guillon, I. Likhachova, and L. Choux. 2020. Mobilizing Private Finance for Nature. Washington, DC: World Bank Group. http://pubdocs.worldbank.org/ en/916781601304630850/Finance-for-Nature-28-Sep-web-version.pdf.

BMU (German Federal Ministry for the Environment, Nature Conservation and Nuclear Safety). 2019. Mobilising Finance for Climate Change Mitigation and Adaptation. Bonn, Germany: International Climate Initiative, BMU. https://www.international-climate-initiative.com/fileadmin/Dokumente/2019/20191021_Mobilising_Climate_Finance.pdf.

Browder, G., S. Ozment, I. Rehberger Bescos, T. Gartner, and G.-M. Lange. 2019 Integrating Green and Gray: Creating Next Generation Infrastructure. Washington, DC: World Bank and World Resources Institute. https://openknowledge. worldbank.org/handle/10986/31430.

Buchner, B., A. Clark, A. Falconer, R. Macquarie, C. Meattle, R. Tolentino, C. Wetherbee. 2019. Global Landscape of Climate Finance 2019, London: Climate Policy Initiative. https://www.climatepolicyinitiative.org/wp-content/uploads/2019/11/2019-Global-Landscape-of-Climate-Finance.pdf.

Buchner, B., M. Herve-Mignucci, C. Trabacchi, J. Wilkinson, M Stadelmann, R. Boyd, F. Mazza, A. Falconer, and V. Micale. 2013. Global Landscape of Climate Finance 2013. London: Climate Policy Initiative. https://www.climatepolicyinitiative.org/wp-content/uploads/2013/10/The-Global-Landscape-of-ClimateFinance-2013.pdf.

Buchner, B., P. Oliver, X. Wang, C. Carswell, C. Meattle, and F. Mazza. 2017. Global Landscape of Climate Finance 2017. London: Climate Policy Initiative. https://www.climatepolicyinitiative.org/wp-content/uploads/2017/10/2017-Global-Landscape-of-Climate-Finance.pdf.

California ARB (Air Resources Board). n.d. "Cap-and-Trade Program." https:// ww2.arb.ca.gov/our-work/programs/cap-and-trade-program.

Caribbean Biodiversity Fund. 2020. The Caribbean Biodiversity Fund Overview. Nassau, Bahamas: Caribbean Biodiversity Fund. https://www.caribbeanbiodiversityfund.org/images/pdf/CBF_Overview_FactSheet_2020.pdf. 
Caribbean Biodiversity Fund. n.d.a. "About Us." https://www.caribbeanbiodiversityfund.org/about-cbf. Accessed November 4, 2020.

Caribbean Biodiversity Fund. n.d.b. Climate Change Program: Ecosystem-Based Adaptation Facility. Nassau, Bahamas: Caribbean Biodiversity Fund. https://www.caribbeanbiodiversityfund.org/images/pdf/CBF_Facility_factSheet_web.pdf. Accessed November 4, 2020.

CBD (Convention on Biological Diversity). n.d. "Article 2. Use of Terms." https://www.cbd.int/convention/articles/?a=cbd-02. Accessed November 4, 2020.

CIF (Climate Investment Funds). n.d.a. "Climate Resilience." https://www. climateinvestmentfunds.org/topics/climate-resilience. Accessed November 4, 2020.

CIF, n.d.b. "Climate Resilience: Championing Big Ambitions." https://www. climateinvestmentfunds.org/sites/cif_enc/files/ppcr_factsheet_web.pdf. Accessed November 4, 2020.

CIF. n.d.c. "Enhancing Renewable Energy Development." https://www.climateinvestmentfunds.org/sites/cif_enc/files/srep_factsheet.pdf. Accessed November 4, 2020.

CIF, n.d.d, "Forests, Development, and Climate: Achieving a Triple Win." https://www.climateinvestmentfunds.org/sites/cif_enc/files/fip_factsheet_0.pdf. Accessed November 4, 2020.

CIF, n.d.e. "Strategic Climate Fund." https://www.climateinvestmentfunds. org/node/5. Accessed November 4, 2020.

CIF. n.d.f. "Sustainable Forests." https://www.climateinvestmentfunds.org/ topics/sustainable-forests. Accessed November 4, 2020.

Claes, J., M. Conway, T. Hansen, K. Henderson, D. Hopman, J. Katz, C. Magnin-Mallez, D. Pinner, M. Rogers, A. Stevens, and R. Wilson. 2020. Valuing Nature Conservation: A Methodology for Quantifying the Benefits of Protecting the Planet's Natural Capital, New York: McKinsey. https://www.mckinsey. $\mathrm{com} / \sim$ media/McKinsey/Business\%20Functions/Sustainability/0ur\%20Insights/Valuing\%20nature\%20conservation/Valuing-nature-conservation.pdf.

Cohen-Shacham, E., A. Andrade, J. Dalton, N. Dudley, M. Jones, C. Kumar, S. Maginnis, et al. 2019. "Core Principles for Successfully Implementing and Upscaling Nature-Based Solutions." Environmental Science \& Policy 98 (August), 20-29. https://doi.org/10.1016/j.envsci.2019.04.014.

Convergence. 2017. Case Study: Seychelles Debt Conversion for Marine Conservation and Climate Adaptation. Nairobi: Convergence. https:// assets.ctfassets.net/4cgqlwde6qy0/2T3Bu04NzGmmAUlc2U0CCg/76b54cea6f027325a0f892d30641f0ef/Convergence__Seychelles_Debt_Conversion_for_Marine_Conservation_and_Climate_Adaptation_Case_ Study__2017.pdf.
Cooper, G., and S. Trémolet. 2019. Investing in Nature: Private Finance for Nature-Based Resilience. London: The Nature Conservancy and Environmental Finance. https://www.nature.org/content/dam/tnc/nature/en/documents/ TNC-INVESTING-IN-NATURE_Report_01.pdf.

CPIC (Coalition for Private Investment in Conservation). n.d. "Blueprints." http://cpicfinance.com/blueprints/. Accessed November 10, 2020.

Davies, C., and R. Lafortezza. 2019. "Transitional Path to the Adoption of Nature-Based Solutions". Land Use Policy 80 (January): 406-9. https://doi. org/10.1016/J.LANDUSEPOL.2018.09.020.

Degnarain, N. 2020. "Debt-for-Climate Swaps: Solving Both the Coronavirus Debt Emergency and the Climate Crisis?" Forbes, April 27. https://www. forbes.com/sites/nishandegnarain/2020/04/27/debt-for-climate-swaps-solving-both-the-coronavirus-debt-emergency-and-the-climate-crisis/.

Deutz, A., G.M. Heal, R. Niu, E. Swanson, T. Townshend, L. Zhu, A. Delmar, A. Meghji, S.A. Sethi, and J. Tobin-de la Puente. 2020. Financing Nature: Closing the Global Biodiversity Financing Gap. Chicago: Paulson Institute; Arlington, VA: The Nature Conservancy; Ithaca, NY: Cornell Atkinson Center for Sustainability. https://www.paulsoninstitute.org/wp-content/uploads/2020/09/ FINANCING-NATURE_Full-Report_Final-Version_091520.pdf.

Egusquiza, A., M. Cortese, and D. Perfido. 2019. "Mapping of Innovative Governance Models to Overcome Barriers for Nature Based Urban Regeneration." IOP Conference Series: Earth and Environmental Science 323: 012081. https:// iopscience.iop.org/article/10.1088/1755-1315/323/1/012081/pdf.

EIB (European Investment Bank). 2018. "Successful Roll-Out of EUR 400m Natural Capital Initiative Supporting Conservation across Europe." May 28. https://www.eib.org/en/press/all/2018-128-successful-roll-out-of-eur-400mnatural-capital-initiative-supporting-conservation-across-europe.

ElB. n.d.a. "Natural Capital Financing Facility: Eligibility." https://www.eib.org/ attachments/documents/ncff_terms_eligibility_en.pdf. Accessed November 4,2020 .

EIB. n.d.b. "Natural Capital Financing Facility (NCFF): In a Nutshell." https:// www.eib.org/en/products/mandates-partnerships/ncff/in-a-nutshell/index. htm. Accessed November 4, 2020.

Einhorn, C., and C. Flavelle. 2020. "A Race against Time to Rescue a Reef from Climate Change." New York Times, December 5. https://www.nytimes. com/2020/12/05/climate/Mexico-reef-climate-change.html.

Estrella, M., and N. Saalismaa. 2013. "Ecosystem-Based DRR: An Overview." In The Role of Ecosystems in Disaster Risk Reduction, edited by F.G. Renaud, K. Sudmeier-Rieux, and M. Estrella, 26-47. Tokyo: United Nations University Press. https://collections.unu.edu/eserv/UNU:1995/ text_808710_9789280812213.pdf. 
European Commission. n.d. "Biodiversity Strategy for 2030-Concrete Actions." https://ec.europa.eu/environment/nature/biodiversity/strategy/ index_en.htm. Accessed December 10, 2020.

FEBA (Friends of Ecosystem-based Adaptation). 2017. Making Ecosystem-based Adaptation Effective: A Framework for Defining Qualification Criteria and Quality Standards, by M. Bertram, E. Barrow, K. Blackwood, A.R. Rizvi, H. Reid, and D. von Scheliha-Dawid. Bonn, Germany: Deutsche Gesellschaft für Internationale Zusammenarbeit; London: International Institute for Environment and Development; Gland, Switzerland: International Union for Conservation of Nature. https://www.iucn.org/sites/dev/files/feba_eba_ qualification_and_quality_criteria_final_en.pdf.

GAFSP (Global Agriculture and Food Security Program). n.d.a. "About Us." https://www.gafspfund.org/about. Accessed November 4, 2020.

GAFSP. n.d.b. "Our Work." https://www.gafspfund.org/our-work. Accessed November 4, 2020.

GCF (Green Climate Fund). 2014. Financial Terms and Conditions of Grants and Concessional Loans. Incheon, Republic of Korea: GCF. https://www.greenclimate.fund/sites/default/files/document/gcf-b06-16.pdf.

GCF. 2019. Report of the Activities of the Secretariat-Addendum l: Development of Sectoral Guidelines and Consultation Process, Incheon, Republic of Korea: GCF. https://www.greenclimate.fund/sites/default/files/document/ gcf-b24-inf08-add02.pdf.

GCF. 2020. Status of Pledges and Contributions Made to the Green Climate Fund. Incheon, Republic of Korea: GCF. https://www.greenclimate.fund/sites/ default/files/document/status-pledges-irm_1.pdf.

GCF. n.d. "Project Preparation Facility." https://www.greenclimate.fund/projects/ppf. Accessed November 4, 2020.

GEF (Global Environment Facility). 2014. GEF Investments on Payment for Ecosystem Services Schemes. Washington, DC: World Bank. https://openknowledge.worldbank.org/handle/10986/20681.

GEF. n.d.a. "Funding." https://www.thegef.org/about/funding. Accessed November 4, 2020.

GEF, n.d.b. "Least Developed Countries Fund-LDCF." https://www.thegef.org/ topics/least-developed-countries-fund-Idcf. Accessed November 4, 2020.

GEF. n.d.c. "Special Climate Change Fund-SCCF." https://www.thegeforg/ topics/special-climate-change-fund-sccf. Accessed November 4, 2020.
GGKP (Green Growth Knowledge Partnership). 2020. Measuring Nature's Contribution to Economic Development: Towards a Framework of Indicators for National Natural Capital Reporting. Geneva: GGKP. https://greengrowthknowledge.org/research/measuring-nature\%E2\%80\%99s-contribution-economic-development-towards-framework-indicators-national.

GIZ (Deutsche Gesellschaft für Internationale Zusammenarbeit). n.d. "Using Ecosystems for Adaptation to Climate Change." https://www.giz.de/en/ worldwide/37322.html. Accessed December 10, 2020.

Global Commission on Adaptation. 2019. Adapt Now: A Global Call for Leadership on Climate Resilience. Rotterdam, Netherlands: Global Commission on Adaptation. https://gca.org/global-commission-on-adaptation/report.

Global Commission on Adaptation. n.d. "Nature-Based Solutions Action Track." World Resources Institute. https://www.wri.org/our-work/project/ global-commission-adaptation/action-tracks/nature-based-solutions. Accessed February 11, 2021.

Global Innovation Lab for Climate Finance. 2019. Restoration Insurance Service Company (RISCO). San Francisco: Climate Policy Initiative. https:// www.climatefinancelab.org/wp-content/uploads/2019/03/RISCO_Instrument-overview-1.pdf.

Global Innovation Lab for Climate Finance. 2020. Monetizing Water Savings. San Francisco: Climate Policy Initiative. https://www.climatefinancelab.org/ wp-content/uploads/2020/09/MWS-2pager-FINAL_280920.pdf.

Government of Mexico. 2016a. Intended Nationally Determined Contribution of Mexico. Bonn, Germany: United Nations Framework Convention on Climate Change. https://www4.unfccc.int/sites/ndcstaging/PublishedDocuments/ Mexic0\%20First/MEXIC0\%20INDC\%2003.30.2015.pdf.

Government of Mexico. 2016b. National Biodiversity Strategy and Action Plan 2016-2030. Tlalpan, Mexico: National Commission for the Knowledge and Use of Biodiversity, Government of Mexico. https://www.cbd.int/doc/world/mx/ mx-nbsap-v2-es.pdf.

Government of Seychelles. 2014. Seychelles National Biodiversity Strategy and Action Plan 2015-2020, edited by J. Nevill, J. Prescott, N.J. Shah, and M.-M. Jeremie. Victoria: Government of Seychelles. http://extwprlegsl.fao.org/docs/ pdf/sey168677.pdf.

Government of Seychelles. 2015. Intended Nationally Determined Contribution (INDC) under the United Nations Framework Convention on Climate Change (UNFCCC). Victoria: Government of Seychelles. https://www4.unfccc.int/ sites/ndcstaging/PublishedDocuments/Seychelles\%20First/INDC\%20of\%20 Seychelles.pdf.

Government of Viet Nam. 2016. Intended Nationally Determined Contribution of Viet Nam. Hanoi: Government of Viet Nam. https://www4.unfccc.int/sites/ ndcstaging/PublishedDocuments/Viet\%20Nam\%20First/VIETNAM'S\%20 INDC.pdf. 
Griscom, B.W., J. Adams, P.W. Ellis, R.A. Houghton, G. Lomax, D.A. Miteva, W.H. Schlesinger, et al. 2017. "Natural Climate Solutions." Proceedings of the National Academy of Sciences of the United States of America 114 (44): 11645-50. https://doi.org/10.1073/pnas.1710465114.

IDB (Inter-American Development Bank). 2020. Increasing Infrastructure Resilience with Nature-Based Solutions (NbS). Washington, DC: IDB. http:// dx.doi.org/10.18235/0002325.

IFAD (International Fund for Agricultural Development). 2020. IFAD Annual Report 2019. Rome: IFAD. https://www.ifad.org/documents/38714170/41784870/ AR2019+EN.pdf/ba495c3d-7db8-a688-08d2-1589ade15f4f.

IFAD. n.d. "Finance." https://www.ifad.org/en/finance. Accessed November 4, 2020 .

IFRC (International Federation of Red Cross and Red Crescent Societies). n.d. Mangrove Plantation in Vietnam: Measuring Impact and Cost Benefit. Geneva: IFRC. http://ifrc-media.org/interactive/wp-content/uploads/2016/06/2.-Mangrove-plantation-in-Viet-Nam.pdf.

llieva, L., and T. Amend. 2019. Emerging Lessons for Mainstreaming Ecosystem-Based Adaptation: Strategic Entry Points and Processes, Bonn, Germany: Deutsche Gesellschaft für Internationale Zusammenarbeit. https://www. international-climate-initiative.com/fileadmin/Dokumente/2019/20190417_ giz2019-en-study_Emerging-lessons-for-EbA-mainstreaming_web.pdf.

IMF (International Monetary Fund). 2019. "Fiscal Policies for Paris Climate Strategies-from Principle to Practice." Policy Paper 19/010. Washington, DC: IMF, https://www.imf.org/en/Publications/Policy-Papers/Issues/2019/05/01/ Fiscal-Policies-for-Paris-Climate-Strategies-from-Principle-to-Practice-46826.

IPBES (Intergovernmental Science-Policy Platform on Biodiversity and Ecosystem Services). 2019. Global Assessment Report on Biodiversity and Ecosystem Services of the Intergovernmental Science-Policy Platform on Biodiversity and Ecosystem Services, edited by E.S. Brondizio, J. Settele, S. Díaz, and H.T. Ngo. Bonn, Germany: IPBES Secretariat.

IPCC (Intergovernmental Panel on Climate Change). 2019. "Summary for Policymakers." In Climate Change and Land: An IPCC Special Report on Climate Change, Desertification, Land Degradation, Sustainable Land Management, Food Security, and Greenhouse Gas Fluxes in Terrestrial Ecosystems, edited by P.R. Shukla, J. Skea, E. Calvo Buendia, V. Masson-Delmotte, H.-0. Pörtner, D.C. Roberts, P. Zhai, et al. Geneva: IPCC.

IUCN (International Union for Conservation of Nature). 2019. Mexico, Central America and the Caribbean Regional Office: Annual Report 2018. San José, Costa Rica: IUCN. https://portals.iucn.org/library/sites/library/files/documents/2019-011-En.pdf.

IUCN. 2020. Global Standard for Nature-based Solutions. A User-Friendly Framework for the Verification, Design and Scaling Up of NbS. Gland, Switzerland: IUCN. https://doi.org/10.2305/IUCN.CH.2020.08.en.
IUCN. n.d. "Global Fund for Ecosystem-Based Adaptation." https://www.iucn. org/theme/ecosystem-management/our-work/ecosystem-based-approaches-climate-change-adaptation/global-fund-ecosystem-based-adaptation. Accessed November 4, 2020.

Kabisch, N., N. Frantzeskaki, S. Pauleit, S. Naumann, M. Davis, M. Artmann, D. Haase, S. Knapp, H. Korn, J. Stadler, K. Zaunberger, and A. Bonn. 2016. "Nature-Based Solutions to Climate Change Mitigation and Adaptation in Urban Areas: Perspectives on Indicators, Knowledge Gaps, Barriers, and Opportunities for Action." Ecology and Society 21 (2): 39. http://www.ecologyandsociety.org/vol21/iss2/art39/.

Kapos, V., S. Wicander, T. Salvaterra, K. Dawkins, and C. Hicks. 2019. "The Role of the Natural Environment in Adaptation." Background Paper. Rotterdam, Netherlands: Global Commission on Adaptation, https://gca.org/reports/ the-role-of-the-natural-environment-in-adaptation/.

Lo, V. 2016. Synthesis Report on Experiences with Ecosystem-Based Approaches to Climate Change Adaptation and Disaster Risk Reduction. Technical Series 85. Montreal: Secretariat of the Convention on Biological Diversity. https://www.cbd.int/doc/publications/cbd-ts-85-en.pdf.

McVittie, A., L. Cole, and A. Wreford. 2017. Assessing Adaptation Knowledge in Europe: Ecosystem-Based Adaptation. Brussels: Directorate-General for Climate Action, European Commission. https://ec.europa.eu/clima/sites/clima/ files/adaptation/what/docs/ecosystem_based_adaptation_en.pdf.

Millennium Ecosystem Assessment. 2005. Ecosystems and Human Well-Being: Synthesis. Washington, DC: Island. http://www.millenniumassessment. org/documents/document.356.aspx.pdf.

NCFA (Natural Capital Finance Alliance). 2018a. Exploring Natural Capital Opportunities, Risks and Exposure: A Practical Guide for Financial Institutions. Oxford, UK: NCFA; Cambridge, UK: United Nations Environment World Conservation Monitoring Centre. https://www.naturalcapital.finance/wp-content/uploads/2018/11/Exploring-Natural-Capital-Opportunities-Risks-and-Exposure.pdf.

NCFA. 2018b. Integrating Natural Capital in Risk Assessments: A Step-byStep Guide for Banks, Oxford, UK: NCFA; London: PricewaterhouseCoopers. https://www.unepfi.org/wordpress/wp-content/uploads/2019/01/Integrating-Natural-Capital-Risk-Assessments.pdf.

OECD (Organisation for Economic Co-operation and Development). 2019a. Biodiversity: Finance and the Economic and Business Case for Action. Report prepared for the G7 Environment Ministers' Meeting, Metz, France, May 5-6. Paris: OECD, https://www.oecd.org/environment/resources/biodiversity/ G7-report-Biodiversity-Finance-and-the-Economic-and-Business-Case-forAction.pdf. 
OECD. 2019b. "Results of The First Survey on Coefficients That Members Apply to the Rio Marker Data When Reporting to the UN Conventions on Climate Change and Biodiversity." Paris: OECD. http://www.oecd.org/dac/financing-sustainable-development/Results\%20of\%20the\%20first\%20survey\%20 on $\% 20$ coefficients\%20that\%20Members\%20apply\%20to\%20the\%20Rio\%20 marker\%20data\%20when\%20reporting\%20to\%20the\%20UN\%20Conventions\%20on\%20Climate\%20Change\%20and\%20Biodiversity.pdf.

OECD. 2020a. Climate Finance Provided and Mobilised by Developed Countries in 2013-18. Paris: OECD. https://doi.org/10.1787/f0773d55-en.

OECD. 2020b. "Nature-Based Solutions for Adapting to Water-Related Climate Risks." Environment Policy Paper 21. Paris: OECD. https://www.oecd-ilibrary. org/docserver/2257873d-en.pdf?expires=1612718649\&id=id\&accname=gu est\&checksum=757A22138699D7DB5648A82A83044CFD.

OECD. n.d. OECD DAC Rio Markers for Climate Handbook. Paris: OECD. http:// www.oecd.org/dac/environment-development/Revised\%20climate\%20 marker\%20handbook_FINAL.pdf.

Omari-Motsumi, K., M. Barnett, and L. Schalatek. 2019. "Broken Connections and Systemic Barriers: Overcoming the Challenge of the 'Missing Middle' in Adaptation Finance." Background Paper. Rotterdam, Netherlands: Global Commission on Adaptation. https://gca.org/reports/broken-connections-and-systemic-barriers-overcoming-the-challenge-of-the-missing-middle-in-adaptation-finance/.

Ozment, S., K. DiFrancesco, and T. Gartner. 2015. "The Role of Natural Infrastructure in the Water, Energy and Food Nexus." Nexus Dialogue Synthesis Paper. Gland, Switzerland: International Union for Conservation of Nature. https://doi.org/10.2305/IUCN.CH.2015.NEX.4.en.

Ozment, S., G. Ellison, and B. Jongman. 2019. Nature-Based Solutions for Disaster Risk Management: Booklet. Washington, DC: World Bank Group. http:// documents.worldbank.org/curated/en/253401551126252092/Booklet.

Powell, N., M. Osbeck, S.B. Tan, and V.C. Toan. 2011. World Resources Report Case Study: Mangrove Restoration and Rehabilitation for Climate Change Adaptation in Vietnam. Washington, DC: World Resources Institute. https:// www.researchgate.net/publication/235602091_Mangrove_restoration_ and_rehabilitation_for_climate_change_adaptation_in_Vietnam.

Puri, J., and A. Khan. 2019. "Climate Impact Bonds and the GCF." Independent Evaluation Unit Blog, Green Climate Fund, December 17. https://ieu.greenclimate.fund/news/new-blog-post-climate-impact-bonds-and-the-gcf.

Republic of Rwanda. 2016. National Biodiversity Strategy and Action Plan. Kigali: Republic of Rwanda. https://www.cbd.int/doc/world/rw/rw-nbsapv2-en.pdf.
Republic of Rwanda. 2020. Intended Nationally Determined Contribution of Rwanda. Kigali: Republic of Rwanda. https://www4.unfccc.int/sites/ndcstaging/PublishedDocuments/Rwanda\%20First/Rwanda_Updated_NDC_ May_2020.pdf

Richmond, M. 2020. "Expanding the Horizon of Climate Adaptation Finance." Climate Policy Initiative Blog, April 9. https://www.climatepolicyinitiative. org/2020/04/09/expanding-the-horizon-of-climate-adaptation-finance/.

Reid, H., S. Kutegeka, and E. Busingye. 2018. Ecosystem-Based Approaches to Adaptation: Strengthening the Evidence and Informing Policy-Research Results from the Mountain EbA Project, Uganda. London: International Institute for Environment and Development. https://pubs.iied.org/17623IIED/.

Saigal, K. 2019. "Conservation Finance: Seychelles' Troubled Waters." Euromoney, October 10. https://www.euromoney.com/article/b1hhzxrs8z0syh/ conservation-finance-seychelles39-troubled-waters.

Sarabi, S., Q. Han, A.G.L. Romme, B. de Vries, R. Valkenburg, and E. den Ouden. 2020. "Uptake and Implementation of Nature-Based Solutions: An Analysis of Barriers Using Interpretive Structural Modeling." Journal of Environmental Management 270 (September): 110749, https://doi.org/10.1016/j. jenvman.2020.110749.

SCBD (Secretariat of the Convention on Biological Diversity). 2009. Connecting Biodiversity and Climate Change Mitigation and Adaptation: Report of the Second Ad Hoc Technical Expert Group on Biodiversity and Climate Change. Technical Series 41. Montreal: SCBD. https://www.cbd.int/doc/publications/ cbd-ts-41-en.pdf.

SCBD. 2019. Voluntary Guidelines for the Design and Effective Implementation of Ecosystem-Based Approaches to Climate Change Adaptation and Disaster Risk Reduction and Supplementary Information. Technical Series 93. Montreal: SCBD. https://www.cbd.int/doc/publications/cbd-ts-93-primer-en.pdf.

Schmalzbauer, A. 2018. Barriers and Success Factors for Effective Co-creating Nature-Based Solutions for Urban Regeneration. Deliverable 1.1.1, CLEVER Cities, H2020 grant no. 776604. https://clevercities.eu/fileadmin/user_upload/Resources/D1.1_Theme_1_Barriers_success_factors_co-creation_ HWWI_12.2018.pdf.

Seddon, N., A. Chausson, P. Berry, C.A.J. Girardin, A. Smith, and B. Turner. 2020a. "Understanding the Value and Limits of Nature-Based Solutions to Climate Change and Other Global Challenges." Philosophical Transactions of the Roya/ Society B 375 (1794): 20190120, http://dx.doi.org/10.1098/rstb.2019.0120.

Seddon N., E. Davis, R. Davis, A. Chausson, R. Harris, X. Hou-Jones, S. Huq, et al. 2020b. "Global Recognition of the Importance of Nature-Based Solutions to the Impacts of Climate Change." Global Sustainability 3 (e15): 1-12. https:// doi.org/10.1017/sus.2020.8. 
Seddon, N., S. Sengupta, M. García Espinosa, I. Hauler, D. Herr, and A.R. Rizvi. 2019. Nature-Based Solutions in Nationally Determined Contributions: Synthesis and Recommendations for Enhancing Climate Ambition and Action by 2020. Gland, Switzerland: IUCN; Oxford, UK: University of Oxford. https:// portals.iucn.org/library/sites/library/files/documents/2019-030-En.pdf.

Somarakis, G., S. Stagakis, and N. Chrysoulakis, eds. 2019. Nature-Based Solutions Handbook. ThinkNature project funded by the EU Horizon 2020 research and innovation program under grant agreement №. 730338. Luxembourg: European Union Publications Office. https://doi.org/10.26225/ jerv-w202.

Sommer, J.M., M. Restivo, and J.M. Shandra. 2020. "The United States, Bilateral Debt-for-Nature Swaps, and Forest Loss: A Cross-National Analysis." Journal of Development Studies 56 (4): 748-64. https://doi.org/10.1080/00220388.20 18.1563683.

Stern, M., and M. Echavarria. 2013a. Investments in Watershed Services for the Jequetepeque Watershed in Northwestern Peru, Departments of Cajamarca and La Libertad. Peru Investments in Watershed Services Series. Washington, DC: Forest Trends. https://www.forest-trends.org/wp-content/uploads/ imported/jequetepeque-iws_-11-5-13-pdf.pdf.

Stern, M., and M. Echavarria. 2013b. Investments in Watershed Services for Moyobamba on Subwatersheds of the Alto Mayo, Department of San Martín, Peru. Peru Investments in Watershed Services Series. Washington, DC: Forest Trends. https://www.forest-trends.org/wp-content/uploads/imported/ alto-mayo-iws_11-5-13_final-pdf.pdf.

Stern, M., and M. Echavarria. 2013c. Investments in Watershed Services for the Rimac Watershed, Department of Lima, Peru. Peru Investments in Watershed Services Series. Washington, DC: Forest Trends. https://www.forest-trends. org/wp-content/uploads/imported/rimac-iws-final_11-5-13-pdf.pdf.

Swiss Re. 2019. "Designing a New Type of Insurance to Protect the Coral Reefs, Economies and the Planet." December 10. https://www.swissre.com/ our-business/public-sector-solutions/thought-leadership/new-type-of-insurance-to-protect-coral-reefs-economies.html.

Tall, A., and C.J. Brandon. 2019. The World Bank Group's Action Plan on Climate Change Adaptation and Resilience: Managing Risks for a More Resilient Future. Washington, DC: World Bank Group. http://documents.worldbank.org/ curated/en/519821547481031999/The-World-Bank-Groups-Action-Plan-onClimate-Change-Adaptation-and-Resilience-Managing-Risks-for-a-MoreResilient-Future.

Terton, A., and J. Greenwalt. 2020. Building Resilience with Nature: Ecosystem-Based Adaptation in National Adaptation Plan Processes. Winnipeg, Canada: NAP Global Network, International Institute for Sustainable Development. https://napglobalnetwork.org/wp-content/uploads/2020/11/napgn-en2020-ecosystem-based-adaptation-in-naps.pdf.
TNC (The Nature Conservancy). 2019. "Insuring Nature to Ensure a Resilient Future." https://www.nature.org/en-us/what-we-do/our-insights/perspectives/insuring-nature-to-ensure-a-resilient-future/.

Travers, A., C. Elrick, R. Kay, and 0. Vestergaard. 2012. "Ecosystem-Based Adaptation Guidance: Moving from Principles to Practice." Nairobi: United Nations Environment Programme.

Trémolet, S., A. Favero, N. Karres, M. Toledo, E. Kampa, M. Lago, G. Anzaldua, et al. 2019. Investing in Nature for Europe Water Security. London: The Nature Conservancy; Berlin: Ecologic Institute; Bonn, Germany: ICLEl. https://www. nature.org/content/dam/tnc/nature/en/documents/Investing_in_Nature_ for_European_Water_Security_02.pdf.

UNEP (United Nations Environment Programme). 2020. "UNEP, IUCN to Launch New €20m Programme on Ecosystem-Based Adaptation." Press Release, January 21. https://www.unenvironment.org/news-and-stories/ press-release/unep-iucn-launch-new-eu20m-programme-ecosystembased-adaptation.

UNEP. 2021. The Adaptation Gap Report 2020. Nairobi: UNEP. https://www. unenvironment.org/resources/adaptation-gap-report-2020.

UNEP. n.d. "Financing Solutions for Sustainable Development: Debt for Nature Swaps." https://www.sdfinance.undp.org/content/sdfinance/en/home/solutions/debt-for-nature-swaps.html .

UNEP, UNEP Finance Initiative, and Global Canopy. 2020. Beyond 'Business as Usual': Biodiversity Targets and Finance. Managing Biodiversity Risks across Business Sectors. Cambridge, UK: UNEP-World Conservation Monitoring Centre. https://naturalcapital.finance/wp-content/uploads/2020/06/BeyondBusiness-As-Usual-Full-Report.pdf.

UNFCCC (United Nations Framework Convention on Climate Change). 2001. "Decision 7/CP.7: Funding under the Convention." Bonn, Germany: UNFCCC. https://unfccc.int/files/cooperation_and_support/financial_mechanism/ application/pdf/7_cp.7.pdf.

United Nations. 2019. "Amid Worsening Climate Crisis, UN Secretary-General Sets Out Top Ten Climate Action Priorities for 2020, Vows to Stay on Frontlines." Sustainable Development Goals, December 11. https://www.un.org/ sustainabledevelopment/blog/2019/12/77358/.

United Nations. n.d. "\#15 Life on Land." Sustainable Development Goals. https://www.un.org/sustainabledevelopment/biodiversity/.

Vietnam Ministry of Natural Resources and Environment. 2019. The Third National Communication of Vietnam to the United Nations Framework Convention on Climate Change. Hanoi: Vietnam Publishing House of Natural Resources, Environment and Cartography. https://www4.unfccc.int/sites/SubmissionsStaging/NationalReports/Documents/260315_Viet\%20Nam-NC3-2-Viet\%20 Nam\%20-\%20NC3.pdf. 
Vietnam Red Cross Society. 2011. Mangrove Plantation and Disaster Risk Reduction Programme. Hanoi: Vietnam Red Cross Society.

Vogl, A.L., J.H. Goldstein, G.C. Daily, B. Vira, L. Bremer, R.I. McDonald, D. Shemie, E. Tellman, and J. Cassin. 2017. "Mainstreaming Investments in Watershed Services to Enhance Water Security: Barriers and Opportunities." Environmental Science \& Policy 75 (September): 19-27. https://doi.org/10.1016/j. envsci.2017.05.007.

Wamsler, C., B. Wickenberg, H. Hanson, J.A. Olsson, S. Stålhammar, H. Björn, H. Falck, et al. 2020. "Environmental and Climate Policy Integration: Targeted Strategies for Overcoming Barriers to Nature-Based Solutions and Climate Change Adaptation." Journal of Cleaner Production 247 (February): 119154. https://doi.org/10.1016/j.jclepro.2019.119154.

Watkins, G.G., M.C. Silva Zuniga, A. Rycerz, K. Dawkins, J. Firth, V. Kapos, L. Canevari, B. Dickson, and A.-L. Amin. 2019. Nature-Based Solutions: Increasing Private Sector Uptake for Climate-Resilience Infrastructure in Latin America and the Caribbean. Washington, DC: Inter-American Development Bank, Climate Change Division. http://dx.doi.org/10.18235/0002049.

WBG (World Bank Group) and Frankfurt School of Finance and Management. 2017. Results-Based Climate Finance in Practice: Delivering Climate Finance for Low-Carbon Development. Washington, DC: World Bank, https://openknowledge.worldbank.org/handle/10986/26644.
WEF (World Economic Forum). 2020a. The Future of Nature and Business Policy Companion: Recommendations for Policy-Makers to Reset towards a New Nature Economy, Geneva: WEF. http://www3.weforum.org/docs/WEF_NNER_ II_The_Future_of_Business_and_Nature_Policy_Companion_2020.pdf.

WEF. 2020b. Nature Risk Rising: Why the Crisis Engulfing Nature Matters for Business and the Economy, Geneva: WEF, http://www3.weforum.org/docs/ WEF_New_Nature_Economy_Report_2020.pdf.

WEF. 2020c. New Nature Economy Report Il: The Future of Nature and Business, Geneva: WEF, http://www3.weforum.org/docs/WEF_The_Future_Of_ Nature_And_Business_2020.pdf.

World Conservation Congress. 2016. Defining Nature-Based Solutions, Gland, Switzerland: International Union for Conservation of Nature. https://portals. iucn.org/library/sites/library/files/resrecfiles/WCC_2016_RES_069_EN.pdf.

World Forum on Natural Capital. n.d. "What Is Natural Capital?" https://naturalcapitalforum.com/about/.

World Ocean Initiative. 2020. "Seychelles Swaps Debt for Nature-World Ocean Initiative." April 8. https://www.woi.economist.com/seychelles-swapsdebt-for-nature/. 
ABOUT THE AUTHORS

Stacy Swann is the Chief Executive Officer and Founding Partner of Climate Finance Advisors (CFA), BLLC.

Laurence Blandford is a Partner at CFA with a track record of over 20 years working on economics, finance, and environmental policy at the international level.

Sheldon Cheng is an Associate at CFA whose work focuses on climate mainstreaming, climate-smart strategies, and advancing investments in resilience.

Jonathan Cook is a Senior Associate in WRI's Climate Resilience practice and helped to lead the Global Commission on Adaptation's action track on Nature-Based Solutions.

Alan Miller is a lawyer with more than 40 years of experience working on global environmental issues, including 16 years in the World Bank Group.

Dr Rhona Barr is an environmental economist with over 15 years of experience in natural resource management and policy.

\section{ACKNOWLEDGMENTS}

The authors would like to acknowledge the Governments of Canada and Denmark for their financial support.

We would like to thank the following reviewers for their helpful comments: Marie-Caroline Badjeck (Government of Canada), Aloke Barnwal (GEF), Valeria Cruz Blancas (Government of Mexico), Carter Brandon (WRI), Christina Chan (WRI), Daniela Chiriac (CPI), Birte Derrix (BMU), Sonja Djukic (Government of Canada), Angela Falconer (CPI), Amb. Patricia Fuller (Government of Canada), Todd Gartner (WRI), Ben Hart (WRI), Valerie Hickey (World Bank), Sumalee Khosla (UNEP), Alex Mackaness (UK Department of Environment, Food \& Rural Affairs), Veronica Galmez Marquez (GCF), Kerry Max (Government of Canada), Federico Mazza (CPI), Gabriela Morales (WRI), Ivo Mulder (UNEP), Ana Cristina Tovalin Plascencia (Government of Mexico), Frances Seymour (WRI), Jason Garth Spensley (GEF), Rod Taylor (WRI), Joe Thwaites (WRI), German Velasquez (GCF), and Alex White (UK Department of Environment, Food \& Rural Affairs).

The authors would also like to thank the following interviewees for their time and insights: Keith Alger (GCF), Gerard Alleng (IDB), Chizuru Aoki (GEF), Maryam Nava Assad (Government of Mexico), Aloke Barnwal (GEF), Birte Derrix (BMU), Mauricio Diaz (Government of Peru), Daniel Frans van Gilst (NORAD), Alfred Hans Grunwaldt (IDB), Gloria Cuevas Guillaumin (Government of Mexico), Fareeha Iqbal (GEF), Brendan Jongman (World Bank), Veronica Galmez Marquez (GCF), Yitebitu Moges (Government of Ethiopia), Ivo Mulder (UNEP), Roberto Piselli (Government of Peru), Ana Cristina Tovalin Plascencia (Government of Mexico), Cindy Patricia Quijada Robles (NORAD), Nathaly Abadia Salinas (Government of Peru), Diego Adrián de León Segovia (Government of Mexico), Hyunjeong Shim (GCF), Jason Garth Spensley (GEF), German Velasquez (GCF), and Mariana Carolina Silva Zuniga (IDB).

We would also like to thank Lauri Scherer for copyediting; Shannon Collins, Rosie Ettenheim, and Romain Warnault for assistance with design and layout; and Nisha Krishnan, Leo Luo, Steven Moser, Karen Piñeros, Nate Shelter, Emilia Suarez, and Carolyn Turkaly for their contributions. 
ABOUT WRI

World Resources Institute is a global research organization that turns big ideas into action at the nexus of environment, economic opportunity, and human well-being.

\section{Our Challenge}

Natural resources are at the foundation of economic opportunity and human wellbeing. But today, we are depleting Earth's resources at rates that are not sustainable, endangering economies and people's lives. People depend on clean water, fertile land, healthy forests, and a stable climate. Livable cities and clean energy are essential for a sustainable planet. We must address these urgent, global challenges this decade.

\section{Our Vision}

We envision an equitable and prosperous planet driven by the wise management of natural resources. We aspire to create a world where the actions of government, business, and communities combine to eliminate poverty and sustain the natural environment for all people.

\section{Our Approach}

\section{COUNT IT}

We start with data. We conduct independent research and draw on the latest technology to develop new insights and recommendations. Our rigorous analysis identifies risks, unveils opportunities, and informs smart strategies. We focus our efforts on influential and emerging economies where the future of sustainability will be determined.

\section{CHANGE IT}

We use our research to influence government policies, business strategies, and civil society action. We test projects with communities, companies, and government agencies to build a strong evidence base. Then, we work with partners to deliver change on the ground that alleviates poverty and strengthens society. We hold ourselves accountable to ensure our outcomes will be bold and enduring.

\section{SCALE IT}

We don't think small. Once tested, we work with partners to adopt and expand our efforts regionally and globally. We engage with decision-makers to carry out our ideas and elevate our impact. We measure success through government and business actions that improve people's lives and sustain a healthy environment. 